\title{
LARVAL CULTURE AND SETTLEMENT OF THE INTERTIDAL GASTROPOD
}

\section{SIPHONARIA AUSTRALIS}

\author{
Stephanie Alissa Marinus
}

\author{
A thesis \\ submitted to Victoria University of Wellington \\ In partial fulfilment of the requirements \\ for the degree of \\ Master of Science in Marine Biology
}

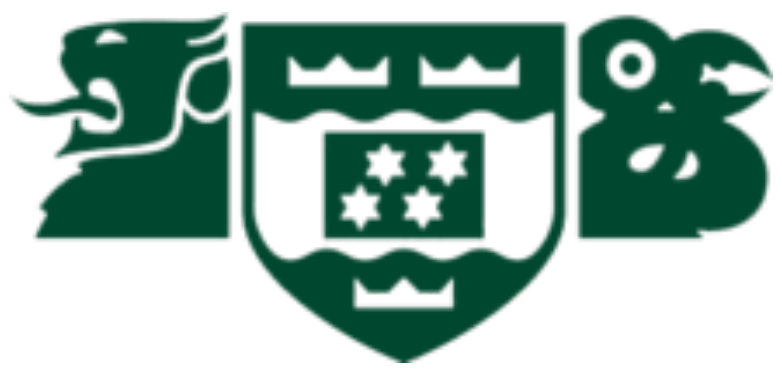

Victoria University of Wellington

Te Whare Wānanga o te Ūpoko o te Ika a Māui

April 2016 


\section{ACKNOWLEDGEMENTS}

I would like to thank all those who helped and supported me from the beginning through to the end of my research. Top of the list goes to my supervisor, Nicole Phillips, for all her guidance, support, encouragement, and advice, all for which I am truly grateful. I consider myself incredibly fortunate to have been chosen as one of her Masters students.

Special thanks goes to Jennifer Howe, whose time and input was thoroughly appreciated, especially when my own time was running out, or when unforeseen algal disasters struck. I would like to thank Gustav Kessel and Agnes Rouchon for contributing their ideas, time, and help with my research. I would also like to express my gratitude to John van der Sman, whose creativity and inquisitive nature aided parts of my experimental set up, as well as his promptness in fixing things I required. Appreciation goes towards Daniel McNaughtan, for making me laugh when times were tough.

Thanks also goes to everyone at VUCEL who undoubtedly would have listened to my despair when unfortunate incidents occurred, and offered me advice and support.

Finally, I thank the Victoria University Coastal Ecology Laboratory (VUCEL) and the School of Biological Sciences (SBS) for providing the facilities for this research.

This thesis is dedicated to my future self, who will look back and read over this and appreciate the determination that went into my very first written thesis. I also dedicate my work to my wonderful parents, whose unfaltering pride it was that made me take this postgraduate step in the first place. 


\section{ABSTRACT}

Laboratory rearing studies on the larvae of benthic marine invertebrates are important in providing information on the development of marine species, particularly those with complex life history cycles. Intertidal gastropods of the genus Siphonaria have been well studied in aspects of their physiology, behaviour, ecology, and reproduction. However, to our current knowledge, there are no cases on the successful laboratory rearing, from hatching through to metamorphosis, of larvae within this genus. Siphonariids are a primitive family of basommatophoran limpets in which the majority produce encapsulated embryos that hatch into feeding, planktonic veliger larvae. For such larvae, the quality and quantity of phytoplankton food can strongly affect larval growth, survival, and the ability to settle and metamorphose successfully. The primary aim of this study was to identify the optimal algal feeding diet for culturing the larvae of Siphonaria australis to competence in laboratory conditions, with a focus on algal composition and quantity. Once having defined the preferred feeding conditions, a secondary aim was to successfully culture larvae through to metamorphosis, by identifying the required settlement cue(s).

First, I exposed newly hatched larvae to diets of three different algal compositions (all at a high concentration of 20,000 cells $/ \mathrm{mL}$ ): two unialgal diets of Isochrysis galbana and Pavlova lutheri, and a mixed diet consisting of a 1:1 ratio of both species. The results revealed that, although they grew in all diets, S. australis larvae exhibited highest growth and survival when fed the unialgal I.galbana diet.

In a second experiment, I exposed newly hatched larvae to three different food concentrations of the unialgal I. galbana diet; low (1,000 cells $/ \mathrm{mL})$, medium (10,000 cells $/ \mathrm{mL})$ and high (20,000 cells/mL). Larval growth and survival were highest when fed a high food concentration, with development and survival severely reduced in low food treatments. At the end of this experiment it was discovered that once larvae grew to $\sim 350 \mu \mathrm{m}$ in length, at an age of approximately one month post-hatching, they began to demonstrate signs of competence and growth rates plateaued.

Finally, I exposed newly hatched larvae to optimum feeding conditions in an attempt to achieve larval settlement using different potential cues. Once larvae began to show signs of competence, they were exposed to five settlement cues: (1) live adults in filtered seawater (FSW), (2) adult-conditioned FSW, (3) rocks in adult-conditioned FSW, (4) rocks in regular FSW, and (5) crustose coralline algae- 
covered rocks in FSW. Larvae only successfully metamorphosed (i.e. exhibited loss of the larval velum) in treatments containing live adults.

In total, my results provide a successful method in culturing Siphonaria australis larvae in laboratory conditions, as well as determines the cue required to induce settlement and metamorphosis. Not only can this method aid in providing more information on the development of this species, but it may also be applied to other members in this genus as well, and further our knowledge on the overall biology of Siphonariid limpets. 


\section{Table of Contents}

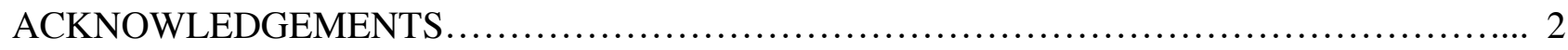

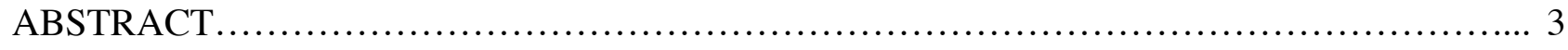

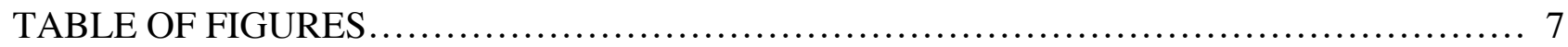

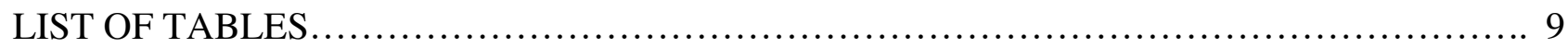

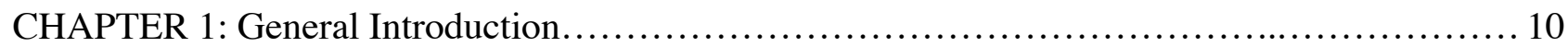

CHAPTER 2: Defining the optimal diet for the laboratory culture of Siphonaria australis......... 17

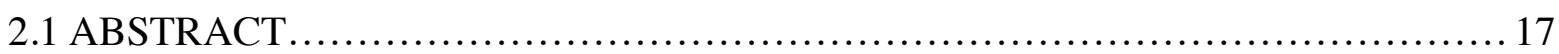

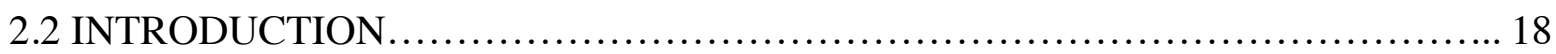

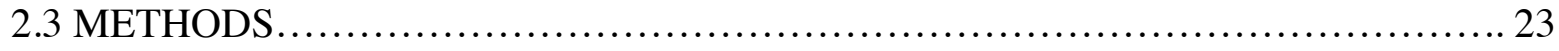

2.3.1 Collection of Adults and Egg Masses................................ 23

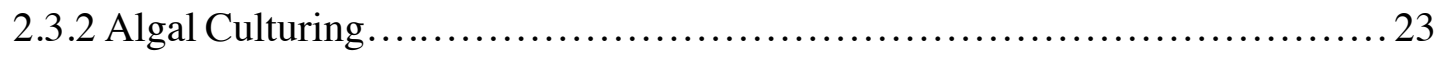

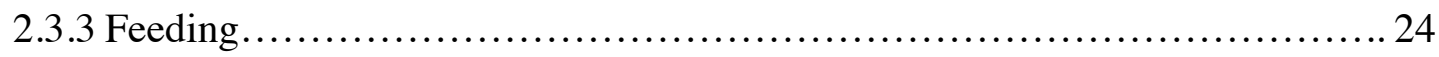

2.3.4 Water Changes, Growth, and Survival Measurements.................... 24

2.3.5 Diet Experiments................................................. 25

2.3.5.1 Experiment 1: Algal Composition........................... 25

2.3.5.2 Experiment 2: Food Concentration........................ 26

2.3.6 Statistical Analyses.............................................. 26

2.3.6.1 Larval Growth......................................... 26

2.3.6.2 Larval Survival........................................... 26

2.4 RESULTS.......................................................... 27

2.4.1 Experiment 1: Algal Composition................................. 27

2.4.1.1 Larval Growth............................................ 27

2.4.1.2 Larval Survival.......................................... 29

2.4.2 Experiment 2: Food Concentration............................... 29

2.4.2.1 Larval Growth.......................................... 29

2.4.2.2 Larval Survival.......................................... 31

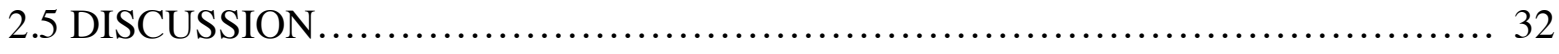

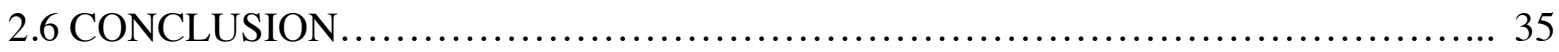

CHAPTER 3: Determining the required cues to induce settlement and metamorphosis in

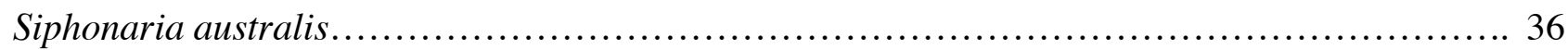

3.1 ABSTRACT ....................................................... 36

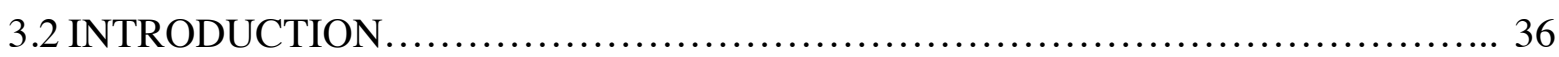




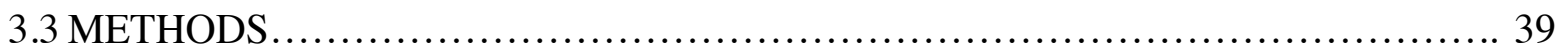

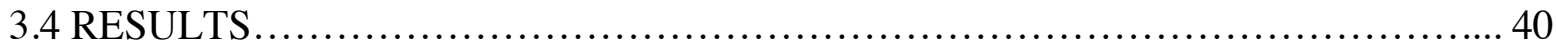

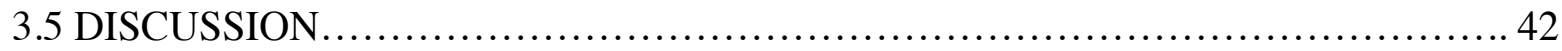

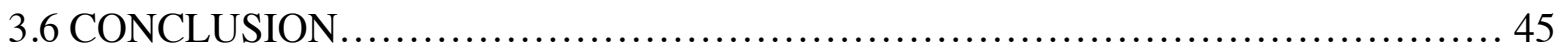

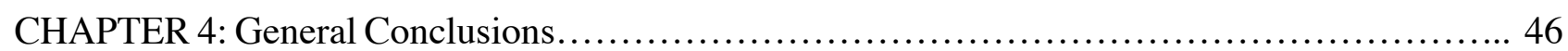

4.1 Summary of Results.................................................... 46

4.2 Future Directions....................................................... 50

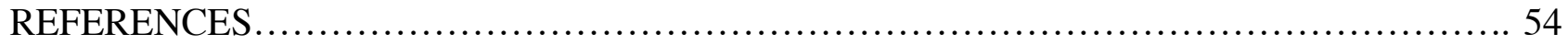

APPENDIX: Pilot studies for optimising laboratory culture techniques for

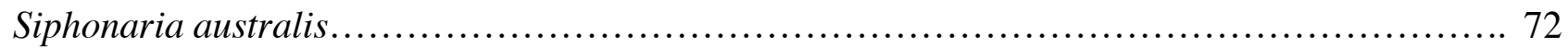




\section{Table of Figures}

Figure 2.1. (a) Adult $S$. australis in the rocky intertidal zone at Princess Bay, Wellington, New Zealand; (b) Adult $S$. australis alongside newly deposited egg masses within the tank set up at Victoria University Coastal Ecology Lab (VUCEL), Wellington, New Zealand; (c) S. australis embryos during early development in the egg mass (at 100x magnification); (d) Newly hatched $S$. australis larvae under the compound microscope (at 100x magnification)

Figure 2.2 Shell length of a newly hatched S. australis larvae being measured beneath a compound microscope (100x magnification)

Figure 2.3 Mean S. australis larval size $(\mu \mathrm{m})$ when subjected to different algal diets over time $( \pm$ $\mathrm{SE}), \mathrm{n}=50$ for each treatment per PDT. Day 0 represents mean larval hatching sizes. 28

Figure 2.4 Mean cumulative survival percentage of $S$. australis larvae when subjected to different algal diets over time $( \pm \mathrm{SE}), \mathrm{n}=5$ per treatment per PDT.

Figure 2.5 Mean S. australis larval size $(\mu \mathrm{m})$ when subjected to different $I$. galbana food concentrations over time $( \pm \mathrm{SE}), \mathrm{n}=10$ for each available replicate per treatment per PDT. Day 0 represents mean larval hatching sizes.

Figure 2.6 Mean cumulative survival percentage of $S$. australis larvae when subjected to different $I$. galbana food concentrations over time $( \pm \mathrm{SE}), \mathrm{n}=5$ per treatment per PDT (excluding medium treatments on Day 27, where $n=3$ ).

Figure 3.1 Shell length of an S. australis larvae nearing competence, measured beneath a compound microscope (100x magnification). Note the display of the foot and the eyespot.

Figure 3.2 Newly settled and metamorphosed S. australis juvenile at 4.4x magnification, beneath a dissecting microscope.

Figure 3.3 Newly settled and metamorphosed S. australis juveniles (arrows) on the shell of an adult, beneath a dissecting microscope at $1.1 \mathrm{x}$ magnification. 
Figure A1: (a) Overall bubbling apparatus measuring 670mm x 27mm; nozzles drilled and glued $\sim 50 \mathrm{~mm}$ from meshed end of tube; (b) closer view of the black adaptor nozzles glued onto pipe; (c) bird's eye view of apparatus, showing meshed end and perspex surrounding the pipe.... 75

Figure A2: Experimental set up incorporating bubbling mechanism in beakers of culturing larvae

Figure A3: Statistical analyses of algal diet trial in March 2015: (a) Mean S. australis larval size $(\mu \mathrm{m})$ when subjected to different algal diets over time $( \pm \mathrm{SE}), \mathrm{n}=40$ per treatment per days from hatching: (b) non-accumulated survival percentage of $S$. australis over time (grouped into weeks), $\mathrm{n}$

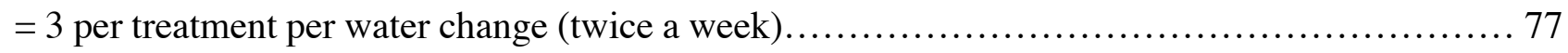




\section{List of Tables}

Table 2.1 Summary of nested one-way ANOVA results examining effects of algal diet on S. australis larval growth on each post-hatching development date. Bold p-values indicate significance at a level of 0.05 . 28

Table 2.2 Summary of nested one-way ANOVA results examining effects of I. galbana concentrations on S. australis larval growth on each post-hatching development date. Bold p-values indicate significance at a level of 0.05 . 31 


\section{Chapter 1. General Introduction}

\section{Larval Life Histories}

Marine invertebrates exhibit an expansive range of life history strategies involving various reproductive and developmental modes (Thorson, 1950). Early larval development occurs via one of three main developmental processes; planktotrophic (feeding larvae), lecithotrophic (non-feeding larvae or direct development), or mixed development. A larval life cycle exhibiting mixed development is considered complex, as it simultaneously incorporates direct and pelagic developmental aspects (Mileikovsky, 1971; Pechenik, 1979). This reproductive pattern can be observed in many marine gastropod species. Here, parents deposit their embryos within either a gelatinous or encapsulated benthic egg mass upon rocks or other substrata (Thorson, 1950; Vance, 1973; Pechenik, 1979; Russell \& Phillips, 2009a). Embryos develop within the capsules for a certain period of time (generally days to weeks) and emerge as planktonic, free-swimming veliger larvae which, thereafter, spend several weeks feeding and developing within the water column before metamorphosing into juveniles back onto benthic substrates (Thorson, 1950; Pechenik, 1979).

Because planktotrophic larvae spend a portion of their developmental period in the water column, the duration of the larval stage can affect larval dispersal and recruitment among marine populations. Estimates of larval duration (or larval life span) are used to predict several important aspects of larval biology, such as dispersal capabilities (Thorson, 1961; Scheltema, 1974; Ayal \& Safriel, 1982), recruitment success (Jackson \& Strathmann, 1981), and life history strategies (Ayal \& Safriel, 1982). Despite the importance of clarifying larval duration, little is known about actual life spans larvae experience in the plankton, as it is difficult to track direct assessments for such minute organisms in the vast three dimensional space of the ocean. Information we have managed to obtain has come from laboratory experiments, yet it is important to note the environmental conditions (e.g. temperature, light, and food) that planktotrophic larvae experience in the field differ markedly from those used in laboratory experiments, and so a laboratory model may not identically simulate conditions in the plankton (Strathmann, 2014). At this stage in time, however, laboratory culturing is the ideal method for obtaining an insight towards what larvae experience in nature. 


\section{Larval Culturing}

Laboratory rearing studies on the larvae of benthic marine invertebrates are important in providing information on larval behaviour, growth rates, estimates of larval duration, and knowledge of the abiotic and biotic factors that control larval development and induce metamorphic competence (Perron, 1980). This information can be applied to important marine biology fields such as aquaculture, where the rearing of marine organisms under controlled environmental and feeding conditions is of vital importance. Aquaculture is a worldwide primary industry that is rapidly growing in response to an increasing global demand for seafood (FAO, 2012). Over time, the number of globally farmed marine species have diversified as farmers express their interest in expanding aquaculture practices to include other species that may benefit humans commercially, whether it be for food or pharmaceutical purposes (Noble et al., 2015). Larval culturing benefits this industry as it allows us to attempt to mass produce commercially important species in response to global demand, as well as understand the life history and population dynamics of the target species, so that we may produce these species in a sustainable way. There is vast literature on the important applications of larval culture in regards to aquaculture, where a lot has been learned about optimal conditions for raising, settling, and sustaining a variety of commercially important species (see Perumal et al., 2015).

\section{Importance of Food Quality and Quantity}

Planktotrophic larvae fuel their growth and development by feeding on exogenous food resources until they are competent to metamorphose. The growth rate of larvae during the pre-competent period dictates the minimum duration of the planktonic stage (Bell, 1993). When growth is rapid, larval life span can be short, reducing the potential for increased dispersal and duration of exposure to planktonic predators (Thorson, 1950). Many factors influence growth rate (e.g. larval density, temperature, salinity, and nutrition), and their relative importance has been difficult to resolve in the field. Two principal factors that have been examined extensively in laboratory studies are temperature and nutrition (Scheltema, 1986; Pechenik et al., 1990; Hoegh-Guldberg \& Pearse, 1995). The relative impact of these factors on larval growth rate may change depending on the environment. For example, tropical oceans, in contrast to temperate ones, have narrower temperature ranges and lower plankton biomass (Raymont, 1980) and in such an environment, nutrition, rather than temperature, may have a greater influence on the range of larval life span (Bell, 1993). In temperate waters, where food and temperature are more likely to fluctuate over space and time, both may be influential on larval duration in the plankton (Valiela, 1984). 
The larval period will be relatively short if nutrition and temperature are optimal, and longer if conditions are sub-optimal (Pechenik, 1984; Hoegh-Guldberg \& Pearse, 1995; Pechenik et al., 2003). A larva's chance of being eaten increases the longer it remains in the plankton, and the smaller its size (Thorson, 1950). Compared to a slow-growing larva, a fast-growing larva has a reduced risk of mortality by being larger and by shortening the time frame from hatching to metamorphic competence. Thus the influence of temperature and nutrition on larval life span affects not only the ability to disperse to appropriate benthic habitats for recruitment, but also the number of larvae available for recruitment (Thorson, 1966). While the influence of a physical environmental factor such as temperature, on larval development and growth, has been well established (Scheltema, 1967; Pechenik, 1984; Miller \& Emlet, 1999; Pechenik et al., 2003) and is easily controlled in laboratory conditions, a biological factor such as nutrition includes many variables, and questions still remain about the role of nutrition in larval development.

Considerable debate has centred on whether larvae are food limited in the ocean (Olson \& Olson, 1989; Hoegh-Guldberg \& Pearse, 1995; Klinzing \& Pechenik, 2000). Given that food resources exhibit levels of patchiness within the marine environment, the majority of larvae may naturally be food limited (Olson \& Olson, 1989; Klinzing \& Pechenik, 2000). However, although the effect of natural variation in food during the planktonic period may be slight, there is evidence that limited food concentrations influence not only larval development but also larval behaviour and physiology (Fenaux et al., 1994; Pechenik et al., 1996b). This raises the question of whether food limitation can have important repercussions on larval recruitment success.

A range of studies have shown larvae responding to limited food availability or starvation with reductions in growth, developmental rates, physiological performance, and behaviour; in molluscs (Strathmann et al., 1993; Pechenik et al., 1996b; Klinzing \& Pechenik, 2000; Phillips, 2002; 2004; Wacker \& von Elert, 2002; Chiu et al., 2007), echinoderms (Fenaux et al., 1994; Basch \& Pearse, 1996), crustaceans (Kon, 1979; Paul \& Paul, 1980; Miller \& Emlet, 1999), and polychaetes (Qian et al., 1990; Qian \& Pechenik, 1998). Larval food supply can have a strong effect on larval growth and development, with low food availability inducing slower larval growth rates, and remaining smaller overall compared to those fed on higher food diets (Qian \& Chia, 1993; Allison, 1994; Phillips, 2002; 2004). In relation to recruitment success, this can provide a disadvantage as smaller larvae are likely to spend more time within the plankton, attempting to grow in order to reach competence, compared to larger, better fed larvae. This means extending exposure to mortality risks and offshore currents (Thorson, 1950). Some studies have also shown evidence of developmental plasticity in some larvae in response to food limitation; for example, increased size in feeding structures (Strathmann et al., 
1992; Fenaux et al., 1994; Klinzing \& Pechenik, 2000), changes in body composition (Chino et al., 1994; Basch \& Pearse, 1996), and impaired behaviour towards metamorphosis by increasing time to reach settlement and reduced selectivity in settlement substrates (Basch \& Pearse, 1996; Pechenik et al., 1996b).

Initially, studies on the effects of food limitation focused more on food quantity impacts on larval development. However, over time, research has deduced that marine invertebrate larvae vary in their nutritional requirements for development, meaning that the nutritional quality of a phytoplankton species is dependent on the larval species in question. This led to food quality becoming extensively studied, to clarify the specific nutritional needs of a species, as well as research into the possibility of food quality being an influential factor in larval development, either separately or synergistically with food availability.

Food quality can vary significantly amongst or within phytoplankton species grown in differing environmental conditions (Pechenik, 1987; Strathmann, 1987), potentially enhancing the degree of food deprivation planktonic feeding larvae may experience during all or part of their development (Hansson et al., 1990; Fenaux et al., 1994). Some research has demonstrated that larval developmental feeding rates can display sensitivity to variations in planktotrophic nutritional quality (HoeghGuldberg \& Pearse, 1995; Klinzing \& Pechenik, 2000), and so food limitation should not be inferred exclusively to food quantity alone.

Studies of the relationship between the early development of marine invertebrate larvae and the biochemical composition of phytoplanktonic food are becoming more frequent as the importance of larval nutrition becomes increasingly recognised. In terms of affecting larval development, the interaction between food quality and quantity could be considered synergistic if one observes the two factors as co-exisiting functions of food from both an energetic and nutritional aspect (Vos et al., 2000). For example, compounds (e.g. carbohydrates) with a high energy content can be easily respired, so that when food availability is low, energy becomes the growth-limiting factor. The addition of high-energy compounds could then counteract this, and any growth limitations could then be due to nutritional quality (Vos et al., 2000).

Food quality can be an important factor in the regulation of invertebrate development as it varies temporally and spatially, similar to food quantity (Klinzing \& Pechenik, 2000; Vos et al., 2000). Algal properties can be influenced by strong seasonal fluctuations, subjecting them to certain degrees of microbial degradation and chemical oxidation (Bowen, 1987; Canuel \& Martens, 1993; Kreeger et 
al., 1997), which can result in lowered food quality at points in time and/or space during the larval feeding stage. In many larval culturing experiments, where planktotrophic larvae are reared on cultured algae, several factors relating to algal quality need to be taken into consideration when attempting to replicate natural larval diets. These include factors such as algal age, varying sizes/shapes of algal cells, cell wall texture and composition, and algal cell motility; each can influence algal edibility and food value, as well as impact how larvae respond to food treatments (Strathmann, 1987).

\section{Settlement Cues and Metamorphosis}

Larval life history, settlement and metamorphosis are essential processes which can determine the population structure and dynamics of benthic marine invertebrates (Kempf, 1981; Pawlik \& Hadfield, 1990; Plaut et al., 1995). The processes that lead to the colonisation of substrata by larval invertebrates are among the most important in determining the ecology of marine communities (Pawlik, 1992). Variability in the spatial and temporal patterns of larval recruitment may be attributed to a multitude of factors that are brought into play before, after, or at the time of settlement. An important presettlement factor is the availability of competent larvae, which can be influenced by larval nutritional history (Olson \& Olson, 1989; Pechenik et al., 1996a).

Most benthic marine invertebrates produce pelagic larvae that spend hours to months in the water column before settling and metamorphosing into their adult forms. Before the benthic phase for pelagic larvae can begin, they must get in contact with an acceptable substrate on which to attach themselves (Pawlik, 1992). Studies in both the laboratory and field have provided extensive evidence that there is an active role played by larvae in exercising substrate selectivity at the time of settlement (Crisp, 1974; Watanabe, 1984; Raimondi, 1988). There is also accumulating evidence that larvae of many species can prolong their planktonic existence in the absence of a suitable settlement cue (Pawlik \& Hadfield, 1990; Hadfield \& Paul, 2001).

Invertebrate larvae are exposed to multiple environmental factors during their lives in the plankton and at the time of settlement, and undoubtedly respond to a number of complex and highly specific environmental stimuli in the course of substratum selection (Crisp, 1974; Burke, 1983; Hadfield, 1986; Pawlik, 1992). Studies have demonstrated behavioural responses of larvae to several physical factors (Crisp \& Barnes, 1954; Wethey, 1986; Raimondi, 1990; Walters \& Wethey, 1996), but for the majority of marine species, the most prominent cues seem to emanate from biological sources with particular chemical characteristics (Pawlik \& Hadfield, 1990). For example, certain free fatty acids 
in the chemistry of the tube cement of adult Phragmatopoma lapidosa californica triggers larval settlement (Pawlik, 1986; Pawlik \& Faulkner, 1986); larvae of Balanus amphrite will settle in the presence of specific soluble peptides released by adult barnacles (Rittschof, 1985); and abalone larvae will settle when water-soluble extracts containing the phycobiliproteins of the crustose coralline red algae of the genera Lithothamnion, Lithopyllum, or Hildenbrandia are present (Morse et al., 1980; Morse \& Morse, 1984; Shepherd \& Turner, 1985).

Understanding the cues which induce larval settlement is particularly important in two human applications; artificial cultivation of marine invertebrates (aquaculture or mariculture), and the prevention of biofouling/spread of invasive species (Pawlik \& Hadfield, 1990). This is because many commercially important, and detrimental, invertebrate species have planktotrophic larvae that settle and metamorphose in response to unknown chemical cues, and this information is necessary in order to successfully mass-produce or control such species. Chemical cues have been implicated in the settlement and metamorphosis of a wide variety of marine invertebrate species, either commercial or non-commercial; in particular, those that form conspecific aggregations (reviewed by Burke, 1986), those that settle on or near a food source (Hadfield, 1978; Switzer-Dunlap, 1978; Morse \& Morse, 1984; Chia \& Koss, 1988), and those that settle on films of microorganisms (Kirchman et al., 1981; Brancato \& Woollacott, 1982). The level of chemical cue specificity is an important factor in the strategy of successful larval settlement and metamorphosis (Hadfield \& Paul, 2001).

\section{Biology of Siphonaria}

Although not considered commercially important, the influence of limpets as grazers, and their interactions with other organisms in intertidal marine ecosystems, has resulted in these gastropods being the subject of extensive investigations (Hodgson, 1999). Aspects of the ecology, behaviour, physiology, and evolution of limpets in general have been reviewed by Branch $(1981 ; 1985 ; 1986)$, Hawkins and Hartnell (1983) and Little (1989).

Limpets of the geographically widespread intertidal pulmonate genus Siphonaria are protandrous hermaphrodites with internal fertilisation (Ocaña \& Emson, 1999). They have featured in many ecological studies that have examined grazer-algal (Voss, 1959; Lubchenco \& Gaines, 1981; Hawkins \& Hartnoll, 1983; Levings \& Garrity, 1986) and intra- and inter-specific interactions (Black, 1979; Creese \& Underwood, 1982; Ortega, 1985). In addition, numerous authors have studied Siphonariids to further our knowledge of gastropod physiology, morphology, behaviour and life history strategies (see Hodgson, 1999). The majority deposit gelatinous benthic egg masses cemented to the rock. The 
larvae which emerge are either free-swimming and planktonic veliger larvae or crawling larvae. The duration of the planktonic phase for this genus is currently unknown.

For the last several years, the intertidal pulmonate limpet Siphonaria australis, endemic to New Zealand, has been used as a model species to examine how environmental stressors such as ultraviolet radiation (UVR), salinity, and temperature can impact early life stages of marine organisms (see: Russell \& Phillips, 2009b; Fischer \& Phillips, 2014). Further, there is evidence that stress experienced as benthic embryos can mediate further responses to stress in the early larval stage (Fischer \& Phillips, 2014). However, it has not been possible to examine carry-over effects of stress across further life stages in detail, including possible interactions with larval feeding history, as larvae of this species have not yet successfully been cultured through to competence nor metamorphosis.

\section{Aims \& Objectives}

The overall aim of this study was to identify the optimal diet for culturing the larvae of $S$. australis successfully to metamorphic competence, whilst simultaneously observing the effects of food quality (i.e. composition) and quantity (i.e. availability) on larval growth and survival, thereby exploring the potential of food limitation as an environmental stressor for this species. This aim is explored in the second chapter, where I examined which algal species composition (i.e. diet) resulted in the highest larval growth and survival, by comparing the effects of unialgal and mixed algal diets at a high food concentration. The most successful diet was then used to examine the effects of food concentration (i.e. availability) on larval growth and survival. The results from this chapter was then used to define the optimum algal diet and concentration for rearing larvae of this species to competence in laboratory conditions. In the third chapter, I used these optimum feeding conditions to culture larvae to competence, where they were exposed to a range of settlement cues to discover which induced settlement and metamorphosis, thereby completing the full culture of this species in laboratory conditions. 


\section{Chapter 2. Defining the optimal diet for the laboratory culture of Siphonaria australis}

\subsection{ABSTRACT}

The aim of this chapter was to identify the best algal diet for culturing larvae of the pulmonate limpet Siphonaria australis, by observing which diet resulted in the greatest larval growth and survival in two experiments.

In the first experiment, three treatments were established; a unialgal Isochrysis galbana diet, a unialgal Pavlova lutheri diet, and a mixed diet of the two species at a 1:1 ratio. All were supplied at a high food concentration of 20,000 cells $/ \mathrm{mL}$. In the second experiment, three food concentrations were tested; low $(1,000$ cells $/ \mathrm{mL})$, medium $(10,000$ cells $/ \mathrm{mL})$, and high $(20,000$ cells $/ \mathrm{mL})$, using only the unialgal I. galbana diet, which had exhibited the highest larval growth and survival in the previous experiment. For both these trials, larvae were measured and counted at intervals of 4-5 days over 27 days of larval development, to record growth and survival rates amongst the different treatments.

From the first experiment, an examination of diet on each sample date showed that there was a significant effect of diet on larval growth early into larval development ( 7 and 11 days post-hatching), where larvae fed the mixed diet exhibited lower growth than those fed the unialgal diets. However, by 15 days post-hatching, all treatments resulted in similar-sized larvae. Algal composition did, however, have a significant effect on larval survival, where the unialgal I. galbana diet exhibited the highest larval survival. For the second experiment, food concentration had a significant effect on larval growth, with larvae growing at a faster rate in high food treatments and much slower in low food treatments. Food concentration also had a significant effect on larval survival, with larvae surviving at a much greater rate in high food treatments. In low food treatments larvae were unable to survive the full trial.

Overall, these results show that algal composition and food quantity affected larval growth and survival differently, and with an aim to achieve maximal levels of both, of the diets trialled here, a unialgal I. galbana food composition at a high concentration was the most successful feeding diet for culturing S. australis larvae in laboratory conditions. 


\subsection{INTRODUCTION}

Over the last few decades, larval culturing studies have increased in frequency, and thereby improved in their methods, due to motivations from scientific research on larval development, physiology, ecology, as well as for applied purposes such as aquaculture.

Environmental factors influencing larval growth can affect the minimum duration of larval development, whilst survival can affect the number of competent larvae which successfully settle and metamorphose (Thorson, 1950; 1961; 1966; Jackson \& Strathmann, 1981). Whilst physical factors, such as temperature, salinity, and light, can be easily controlled, a biological factor such as nutrition is more difficult to manipulate because it incorporates multiple variables. The major variables to consider are food composition and concentration. Because the majority of the growth and/or development of planktotrophic larvae occurs during the pre-metamorphic competence stage (Thorson, 1961), optimising the feeding diet is critical for successful culture.

Phytoplankton represent the natural nutritional base and primary source of bulk nutrients in the aquatic food chain, thereby playing a key nutritional role for planktotrophic larvae (Guedes \& Malcata, 2012). It is important to understand how the wide variability of phytoplankton diversity and abundance in the ocean affects larval growth and survival. Phytoplankton in most areas of the ocean are comprised of many species (Raymont, 1980) and several may be needed to fulfil larval nutritional requirements (Pilkington \& Fretter, 1970; Vos et al., 2000). Diets in larval culturing include using natural plankton as food, artificial chows and feeds, or using cultured algae (Davis \& Guillard, 1958; Walne, 1963; Pillsbury, 1985). Many planktotrophic larval species are conveniently reared on cultured algae, but several points should be considered. Because nutrition and feeding play a vital role in larval growth and development, it is important to know that larvae are getting optimum dietary requirements in order to develop correctly and at a good rate.

Phytoplankton species can vary significantly in their nutritional value, as a result of the existing culturing conditions (Brown et al., 1997). Research has indicated that, during the late-logarithmic growth phase (i.e. maximal cell growth stage), phytoplankton can generally contain $30-40 \%$ protein, 10-20\% lipids, and 5-15\% carbohydrates (Brown et al., 1997; Renaud et al., 1999). When cultured during the stationary phase, the microalgal composition may significantly change (Harrison et al., 1990; Brown et al., 1993), suggesting a strong correlation can exist between an algal species' biochemical composition and its measurable nutritional value. The nutritional value of an algal diet 
is also critically related to its ability to supply essential macro- and micronutrients to the target species (Brown, 2002). Several factors contribute to this value, including cell size, shape, digestibility (i.e. they should have a digestible cell wall structure to make nutrients easily obtainable), biochemical composition, and the specific nutritional requirements of the target organism (as these vary amongst/between species) (Strathmann, 1987; Guedes \& Malcata, 2012). Should any of these factors not meet the nutritional requirements of the target animal, this can lead to difficulty for a larvae to capture/ingest or digest food cells, resulting in a poor nutritional quality of that particular algal species (Strathmann et al., 1972; Pechenik, 1987).

Microalgae provide many phytonutrients, in particular; polyunsaturated fatty acids (PUFAs); for example, eicosapentaenoic acid (EPA), arachidonic acid (AA), and docosahexaenoic acid (DHA), all of which are known to be essential for various marine species (Nichols, 2003), in addition to the growth and metamorphosis of many larvae (Brown, 2002; Becker, 2004; Guedes \& Malcata, 2012). Many phytoplankton species exhibit moderate to high percentages of EPA (7 to 34\%), with prymnesiophytes (e.g. Pavlova spp. and Isochrysis spp.) and cryptomonads (e.g. Chroomonas spp. being reasonably rich in DHA (0.2 to $11 \%$ ), and eustigmatophytes (e.g. Nannochloropsis spp.) and diatoms having high percentages of AA (up to 4\%) (Brown, 2002; Guedes \& Malcata, 2012). Chlorophytes (Dunaliella spp. and Chlorella spp.) are deficient in PUFAs, however some species do contain small levels of EPA (up to 3.2\%), yet are, in general, ascribed as being of poor nutritional value, and thereby unsuitable for use as a monoalgal diet (Brown et al., 1997). Hence, it is important to clarify the systematic differences in the fatty acid contents of microalgae according to their taxonomic group (Guedes \& Malcata, 2012).

Some examples of algal species commonly used as foods in larval culturing include: Dunaliella tertiolecta, a green alga $(6-10 \mu \mathrm{m})$ which is a good food for supporting development through to metamorphosis in several echinoderms (Strathmann, 1971), either alone or mixed with other algal species. It also serves as a good food for growing some bivalves (Walne, 1963), and copepods (Grice, 1971) but is a poor food for the veliger larvae of some species (Pechenik \& Fisher, 1979; Wikfors et al., 1984; Pillsbury, 1985), possibly because of an inadequate lipid content (Wikfors et al., 1984; Brown et al., 1997). Cricosphaera carterae is a gold-brown flagellate where cells (10-18 $\mu \mathrm{m})$ store a carbohydrate, chrysolaminarin, and cells in ageing cultures contain fatty substances that make it a good food for prosobranch veligers (Fretter \& Montgomery, 1968). Isochrysis galbana is a golden brown alga $(5-6 \mu \mathrm{m})$, where cells also store chrysolaminarin and will lose their motility once cultures are over 4 weeks old (Strathmann, 1987). It has been shown to be an excellent food source for small planktotrophs such as mollusc veligers (Davis \& Guillard, 1958; Loosanoff \& Davis, 1963; Bayne, 
1965; Pillsbury, 1985), and for some copepods (Corkett, 1972), yet it is not a good unialgal diet for echinoderm larvae (Hinegardner, 1969), copepod nauplii (Corkett, 1972), nor other larvae that feed on larger algal cells. Pavlova lutheri is a golden brown flagellate (4-6 $\mu \mathrm{m})$ which contains approximately 49\% protein and more lipid than usual in marine phytoplankton (Parsons et al. 1961). It contains relatively high percentages of PUFAs essential to marine diets (Hinchcliffe \& Riley, 1972; Brown, 2002; Guedes \& Malcata, 2012). As a unialgal diet, it is only a poor to fair food for bryozoans (Winston 1977), echinoderm larvae (Hinegardner, 1969; Lucas, 1983) and some mussel larvae (Newkirk \& Waugh, 1980), yet it is a good food, especially if mixed with I. galbana or other small algae, for mollusc veligers (Davis \& Guillard, 1958; Loosanoff \& Davis, 1963; Pilkington \& Fretter, 1970; Chia \& Koss, 1978), and copepods (Iwasaki \& Kamiya, 1977).

Often, planktotrophic larvae grow better when fed a mixture of phytoplankton species than they do on any of the species individually (Davis \& Guillard, 1958; Shiraishi \& Provasoli, 1959; Loosanoff \& Davis, 1963; Bayne, 1965; Pilkington \& Fretter, 1970; Chia \& Koss, 1978). Presumably, a unialgal diet may cause nutritional deficiencies by failing to provide one or more essential nutrients (Shiraishi \& Provasoli, 1959; Pechenik, 1987; Klinzing \& Pechenik, 2000; Puello-Cruz et al., 2009), which can be considered as a form of food limitation. A mixed diet, on the other hand, combines the nutrient contents of more than one algal species, which may mean it is more likely to meet the nutritional requirements of the target organism (Helm, 1977; Puello-Cruz et al., 2009). A mixed diet may therefore allow for better larval growth and development compared to a unialgal diet.

In terms of food quantity, many laboratory studies have shown the deleterious effects of food limitation on larval development. For many marine invertebrate species, larvae reared at low food concentrations typically exhibit slower growth rates and, thereby, prolonged development e.g. in crustaceans (West \& Costlow, 1987; Wehrtmann, 1991), sea stars (Allison, 1994; Basch \& Pearse, 1996), oysters (His \& Seaman, 1992), and gastropods (Pillsbury, 1985; Pechenik et al., 1996b). A delayed development to metamorphic competence prolongs exposure to pelagic predators and offshore currents, meaning food limitation can indirectly decrease recruitment into benthic populations (Thorson, 1950; Vance, 1973; Pechenik \& Fisher, 1979; Roughgarden \& Possingham, 1988). Food limitation can also reduce the ability of some larval species to metamorphose successfully in laboratory conditions (Pechenik et al., 1996b), suggesting that it could impair the ability of larvae to select favourable settlement substrates in the field.

Limpets of the geographically widespread intertidal pulmonate genus Siphonaria are protandrous hermaphrodites with internal fertilisation (Ocaña \& Emson, 1999). Siphonaria australis is commonly 
found on semi-exposed or exposed coasts throughout the mid to lower intertidal zones of New Zealand, generally wedged within rock crevices for which they become shaped to fit (Chambers \& McQuaid, 1994) (Fig. 2.1a). In temperate habitats, spawning tends to be seasonal (Hodgson, 1999). For Wellington, spawning occurs between September and March (Russell \& Phillips, 2009b, Marinus, personal observation), where adults generally lay small benthic gelatinous egg masses (Fig. 2.1b) which hatch into planktonic, veliger larvae after approximately a week (Fig. 2.1c; d); a prime example of a mixed development life history strategy. For the last several years, S. australis has been used as a model species to examine effects of global change on embryonic and early larval development (see: Russell \& Phillips, 2009b; Fischer \& Phillips, 2014). However, to date, this species, nor any other species within the genus, have not been successfully cultured through to settlement and metamorphosis.

In this chapter, the aim was to define the optimal feeding diet for culturing larvae of S. australis, in order to determine the best method for culturing these larvae up to competence (Chapter 3 ). The algal species used were Isochrysis galbana and Pavlova lutheri, for their generally accepted success as excellent food sources for mollusc veligers (Davis \& Guillard, 1958; Loosanoff \& Davis, 1963; Brown, 2002; Guedes \& Malcata, 2012), and specific gastropod veligers (Pechenik, 1980; Pechenik \& Heyman, 1987; Pechenik et al., 1996b; Klinzing \& Pechenik, 2000; Chiu et al., 2007; Fischer \& Phillips, 2014). For these two algal species, a monospecific diet of each has shown to be suitable for rearing veliger larvae. However, a mixture of the two species has often proven to be an even better diet (Davis \& Guillard, 1958; Loosanoff \& Davis, 1963; Bayne, 1965; Pilkington \& Fretter, 1970; Chia \& Koss, 1978), therefore a mixed diet of these two species was also tested. 

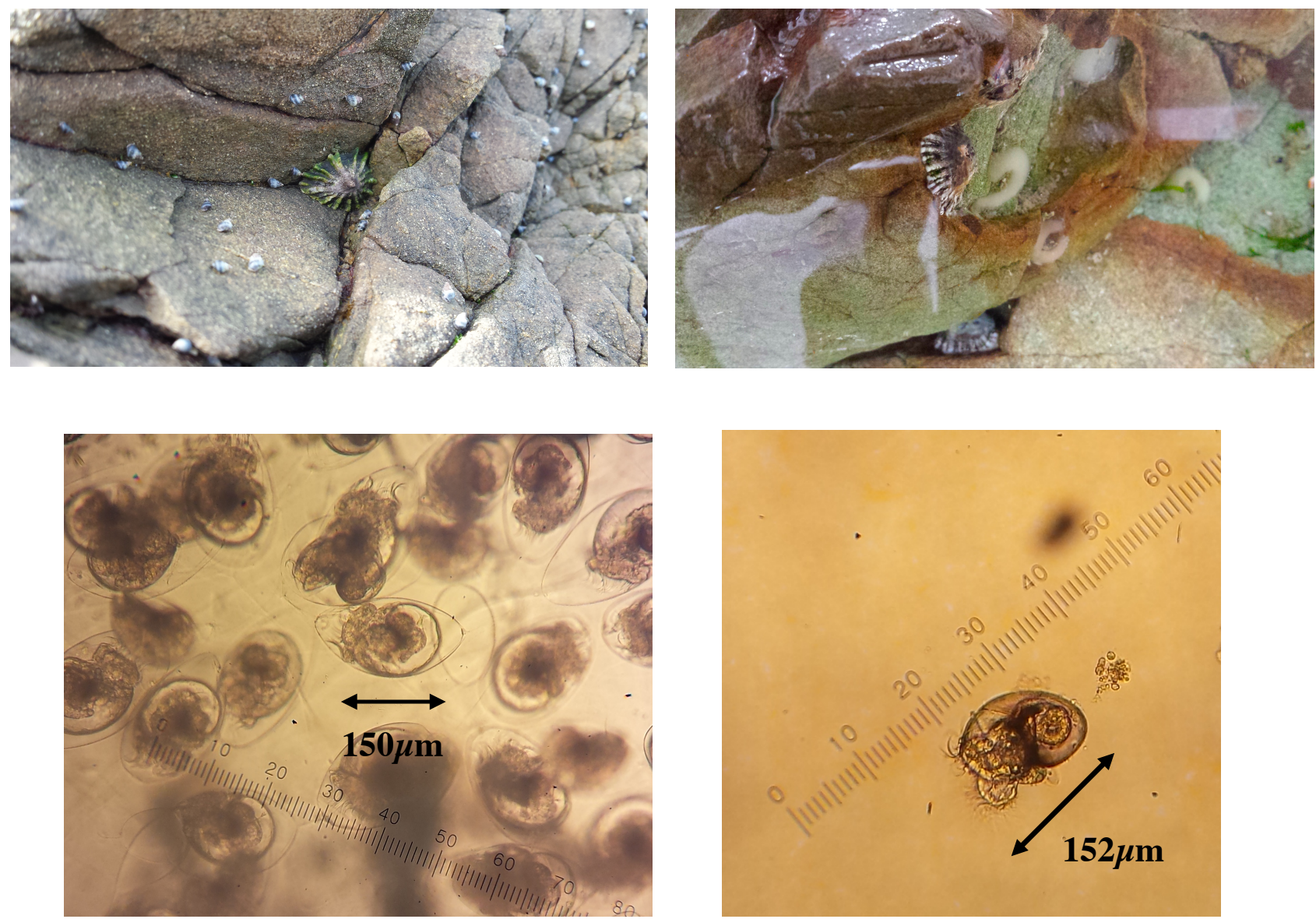

Figure 2.1 (a) Adult S. australis in the rocky intertidal zone at Princess Bay, Wellington, New Zealand; (b) Adult S. australis alongside newly deposited egg masses within the tank set up at Victoria University Coastal Ecology Lab (VUCEL), Wellington, New Zealand; (c) S. australis embryos during early development in the egg mass (at 100x magnification); (d) Newly hatched $S$. australis larvae under the compound microscope (at 100x magnification). Photos taken by: S. Marinus, 2015. 


\subsection{METHODS}

\subsubsection{Collection of Adults and Egg Masses}

Adult S. australis were collected at low tide from intertidal rocky reefs at Princess Bay, Wellington (4120'42.42”S, 17447'12.56”E) between the months of December 2014 to April 2015, and October 2015 to February 2016. Adults were transported to the Victoria University Coastal Ecology Lab (VUCEL) where they were placed into an aquarium $(61.5 \mathrm{~cm} \times 31.5 \mathrm{~cm} \times 31 \mathrm{~cm})$ with flowing ambient seawater ( $\mathrm{n}=10-15$ adults) and rocks collected from the field to allow for continuous grazing. Adults typically deposited egg masses within 24-48 hours of collection.

Within 24 hours of being deposited, egg masses were carefully removed from the tank and maintained in glass dishes of approximately $250 \mathrm{~mL}$ filtered seawater (FSW; filtered with a $0.2 \mu \mathrm{m}$ mesh size filter) and covered with Parafilm to prevent evaporation and contamination. These were put into a temperature-controlled room $\left(17^{\circ} \mathrm{C} \pm 1.6^{\circ} \mathrm{C}\right)$ beneath cool daylight lamps (Philips: TLD 36W/865) set at a 12 hour day:night cycle. Developmental progress towards hatching was checked daily beneath a dissecting microscope, with egg masses rinsed and re-submerged in fresh FSW every second day. Developing embryos took approximately 8-10 days to reach hatching stage.

\subsubsection{Algal Culturing}

The following protocol was used for culturing Isochrysis galbana and Pavlova lutheri in this experiment.

Stock cultures of each species were maintained for frequent harvesting and as a reserve source. Stock cultures past their peak (i.e. judged by time and colouration) were discarded. To make new cultures, clean flasks were rinsed twice with FSW and then filled to 300mL with FSW. Next, Guillard's F/2, a commonly used culture medium for growing marine algae in laboratories, was added. The F/2 used in these cultures was commercially supplied by Aquasonic Pty Ltd. Flasks were then autoclaved at 9-/11-Liquid Cycle (Sterilization Temp: $121^{\circ} \mathrm{C} ; 15 \mathrm{~min}$ ). Once the cycle was completed, and flasks had cooled down overnight, each was inoculated with $\sim 50 \mathrm{~mL}$ of the most recent culture. Algal cultures were kept in the temperature-controlled room, under cool daylight lamps set at a 12 hour day:night cycle and stirred daily. 


\subsubsection{Feeding}

Larvae were fed every 2-3 days. $50 \mathrm{~mL}$ of a healthy culture of each algal species was centrifuged (5 min, $2300 \mathrm{RPM}, 1017 \mathrm{x} \mathrm{g}$ ) and cells were re-suspended with FSW to $20 \mathrm{~mL}$. A small subsample of each species was fixed with two drops of Lugol's solution. Cells in the subsample were counted beneath a compound microscope, at 100x magnification, using a haemocytometer. Calculations were made to determine the amount of feeding stock needed for each algal species and food concentration.

\subsubsection{Water changes, growth, and survival measurements}

Water changes, and growth and survival measurements of larvae, took place once/twice a week, as more frequent water changing lead to higher mortalities, as well as larval loss through transfer (see Appendix). To change the water, first the old culture water in each beaker was reduced to approximately $100 \mathrm{~mL}$ using a reverse-siphon method (Strathmann, 1987) with a $48 \mu \mathrm{m}$ mesh size. The remaining old culture water (and larvae in it) was then gently poured into a glass bowl. Beakers were rinsed and scrubbed in hot tap water, then rinsed with FSW. Beakers were replenished with $500 \mathrm{~mL}$ of FSW and sprinkled with cetyl alcohol, ready for transfer of larvae.

Glass bowls of culture water were individually checked for live larvae using a dissecting microscope (Model: Olympus SZ51). Live larvae (i.e. those still actively swimming or with moving velar lobes) were counted and transferred to a clean beaker with fresh FSW. This has been shown to be the gentlest method for maintaining larval survival of this species (see Appendix). Numbers of survivors were recorded from each beaker and survival rates calculated for each treatment.

For larval growth measurements, 10 larvae per beaker were gently pipetted onto a glass slide and placed beneath a compound microscope (Model: Olympus CX31; Fig. 2.2) where they were measured to the nearest increment with a calibrated ocular micrometer at 100x magnification (Fig. 2.2). In order for measurements to be accurate, larvae had to be oriented in the correct (field) plane that would allow for proper measurement of the shell length. Measurements had to be done promptly to prevent larval mortality, as measured larvae were included as survivors (only live larvae were used for measurements) and returned to their beakers. 
Growth rates were recorded for each treatment. The amount of development time (in days) posthatching was also recorded. Beakers were ended and removed from trials when survival counts were $<10$.

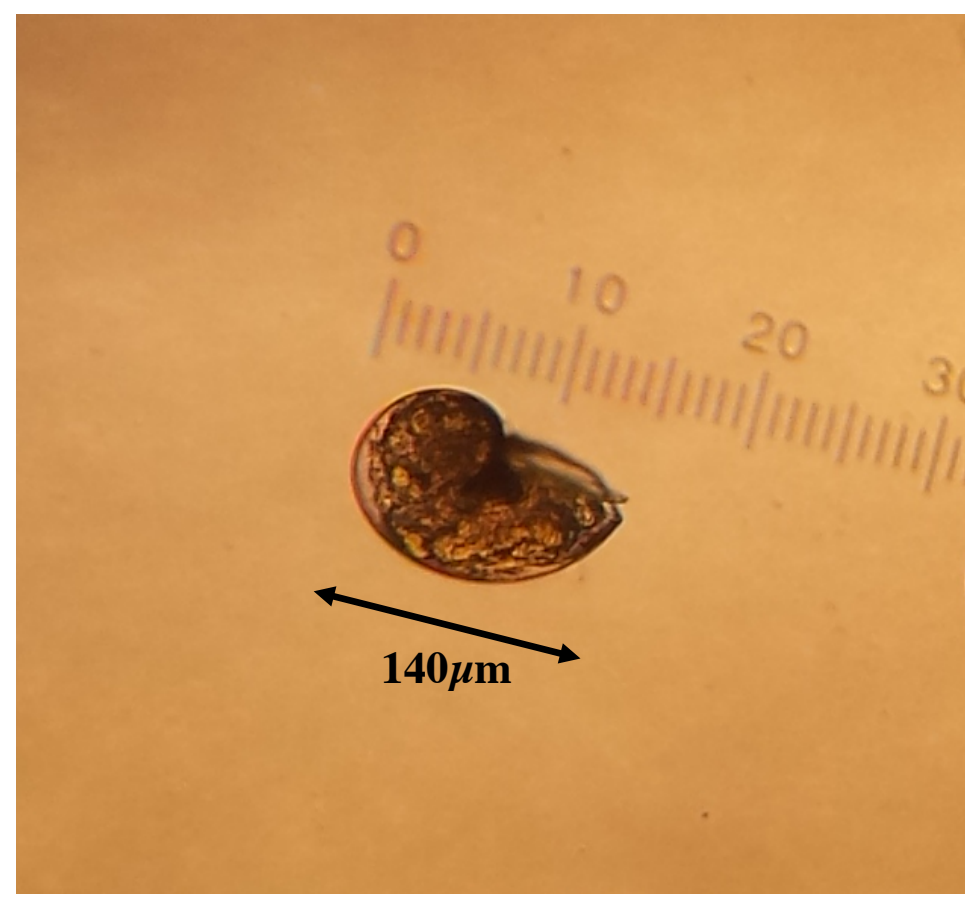

Figure 2.2. Shell length of a newly hatched $S$. australis larvae being measured beneath a compound microscope (100x magnification). Photo taken by: S. Marinus, 2015.

\subsubsection{Diet Experiments}

\subsubsection{Experiment 1: Algal Composition}

This experiment was conducted from October to November 2015, and was designed to examine the effects of algal composition on larval growth and survival rates. Food treatments were established at a high food concentration of 20,000 cells $/ \mathrm{mL}$; a level that has been considered relatively high for other species and unlikely to be limiting (e.g. Phillips, 2002).

Fifteen $500 \mathrm{~mL}$ beakers were filled with FSW and allocated to three diet treatments; PAV (P. lutheri only), ISO (I. galbana only), and MIXED (1:1 P. lutheri: I. galbana), with five replicate beakers per treatment. Actively swimming larvae that had hatched from five egg masses were mixed and 250 larvae were carefully pipetted into each beaker. Beakers were hand-stirred daily. Water changes occurred every four days. 


\subsubsection{Experiment 2: Food Concentration}

This experiment was conducted from December 2015 to January 2016, and was designed to examine the effects of food concentration (i.e. availability) on larval growth and survival rates, using the best diet composition from the previous experiment (ISO).

Fifteen $500 \mathrm{~mL}$ beakers were filled with FSW and assigned to one of three food concentrations of $I$. galbana; low $(1,000$ cells $/ \mathrm{mL})$, medium $(10,000$ cells $/ \mathrm{mL})$, and high $(20,000$ cells $/ \mathrm{mL})$, with five replicate beakers per treatment. Actively swimming larvae that had hatched from five egg masses were mixed and 250 larvae were carefully pipetted into each beaker. Beakers were hand-stirred daily. Here, water changes occurred every 5 days because of logistical constraints.

For both experiments, trials were terminated at 27 days.

\subsubsection{Statistical Analyses}

\subsubsection{Larval Growth}

To examine the effects of algal composition and quantity on larval growth, separate mixed model ANOVA's were conducted, with food treatment and post-hatching development time (hereby called PDT) as fixed factors, beaker replicates nested within treatments, and PDT as a random factor. Because development time had such a strong effect on growth, examination of possible diet effects were further explored with separate mixed one-way ANOVAs on each sample date. Although data violated assumptions of normality and equal variances, data transformations did not improve these assumptions. Given that visually assessing normality plots showed that data was not far off from normality, and that ANOVA's are generally robust to slight deviations from underlying assumptions (Glass et al., 1972), I proceeded with parametric tests.

\subsubsection{Larval Survival}

To examine the effects of algal composition and quantity on larval survival, separate general linear models were used, with food treatment and PDT as fixed factors. Significant results were further examined by post-hoc Tukey tests. Survival percentage data were arc-sine square-root transformed to improve normality and equality of variances before analysis. While transformed data were used for analyses, raw data was plotted for easier interpretation. 
All statistical analyses were carried out using SPSS Statistics (Version 21) software.

\subsection{RESULTS}

\subsubsection{Experiment 1: Algal Composition}

\subsubsection{Larval Growth}

Algal composition did not have a significant effect on larval growth $\left.\left(\mathrm{F}_{1,54.03}\right)=1.489, \mathrm{p}=>0.05\right)$. There was also no significant interaction between algal composition and PDT $\left(\mathrm{F}_{1,54.04}\right)=0.388, \mathrm{p}=>$ 0.05). However, PDT had a significant effect $\left.\left(\mathrm{F}_{5,54.07}\right)=1.489, \mathrm{p}<0.001\right)$, with larvae nearly doubling in size over the 27 days of the experiment (Fig. 2.3). Due to this strong effect, individual nested oneway ANOVAs were conducted to identify whether there were effects of algal composition on the different sample dates. Results showed that algal composition had a significant effect on larval growth early in development; on Day 7 PDT $\left.\left(\mathrm{F}_{2,12}\right)=4.822, \mathrm{p}=0.029\right)$ and Day $11 \operatorname{PDT}\left(\mathrm{F}_{2,9.8}\right)=4.948, \mathrm{p}=$ 0.033, Table 2.1), but not on the other days. On comparing algal composition on both these days, there were no significant differences found between the ISO and MIXED diets, nor between the ISO and PAV diets, however, there was a significant difference between the MIXED and PAV diets, with the MIXED diet exhibiting lower larval growth (post-hoc tests; Fig. 2.3). By Day 15, larvae in all treatments were similar in size, and became more so with time (Fig. 2.3). A summary of these results is shown in Table 2.1 . 


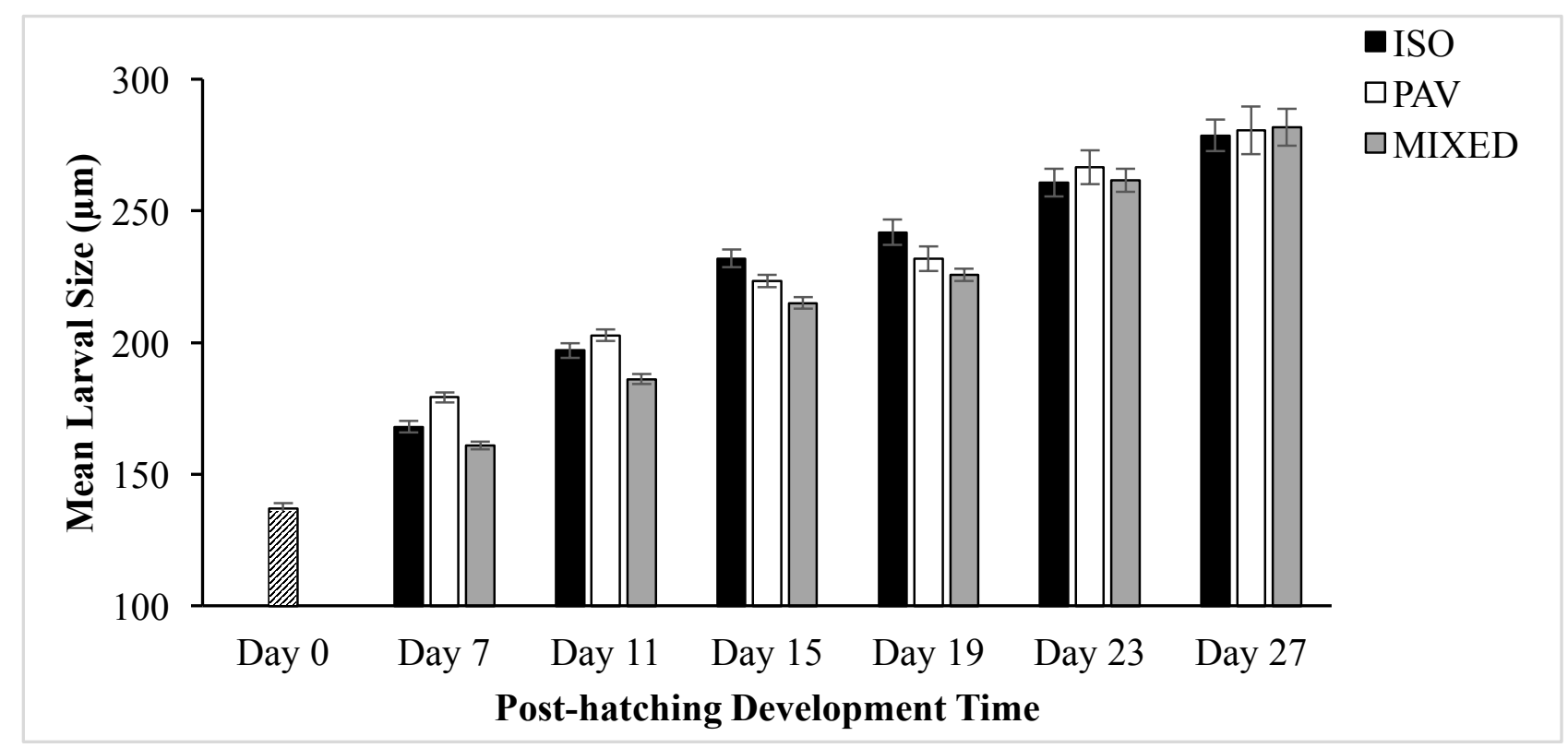

Figure 2.3 Mean S. australis larval size $(\mu \mathrm{m})$ when subjected to different algal diets over time $( \pm$ $\mathrm{SE}), \mathrm{n}=50$ for each treatment per PDT. Day 0 represents mean larval hatching sizes.

Table 2.1 Summary of nested one-way ANOVA results examining effects of algal diet on S. australis larval growth on each post-hatching development date. Bold p-values indicate significance at a level of 0.05 .

\begin{tabular}{|l|r|r|r|}
\hline \multicolumn{1}{|c|}{ PDT } & F & \multicolumn{1}{|c|}{ df } & \multicolumn{1}{c|}{ p } \\
\hline 7 & 4.822 & 2,12 & $\mathbf{0 . 0 2 9}$ \\
\hline 11 & 4.948 & $2,9.8$ & $\mathbf{0 . 0 3 3}$ \\
\hline 15 & 1.509 & 2,8 & 0.278 \\
\hline 19 & 0.459 & $2,8.01$ & 0.647 \\
\hline 23 & 0.038 & 2,7 & 0.963 \\
\hline 27 & 0.010 & $2,7.17$ & 0.990 \\
\hline
\end{tabular}




\subsubsection{Larval Survival}

Larval survival decreased significantly over time $\left.\left(\mathrm{F}_{5,72}\right)=8.751 \mathrm{p}<0.001\right)$, and algal composition also had a significant effect $\left.\left(\mathrm{F}_{2,72}\right)=29.410, \mathrm{p}<0.001\right)$, however there was no significant interaction between the two factors $\left(\mathrm{F}_{10,72}=0.093, \mathrm{p}=>0.05\right)$. The ISO diet exhibited greatest larval survival compared to the PAV and MIXED diets, neither of which were significantly different from each other (post-hoc Tukey test, Fig. 2.4). Day 7 had the highest larval survival compared to all other PDTs (post-hoc Tukey test, Fig. 2.4). By Day 27 there were approximately twice as many larvae left alive in the ISO treatment compared to the others, and very low survival in the PAV treatment.

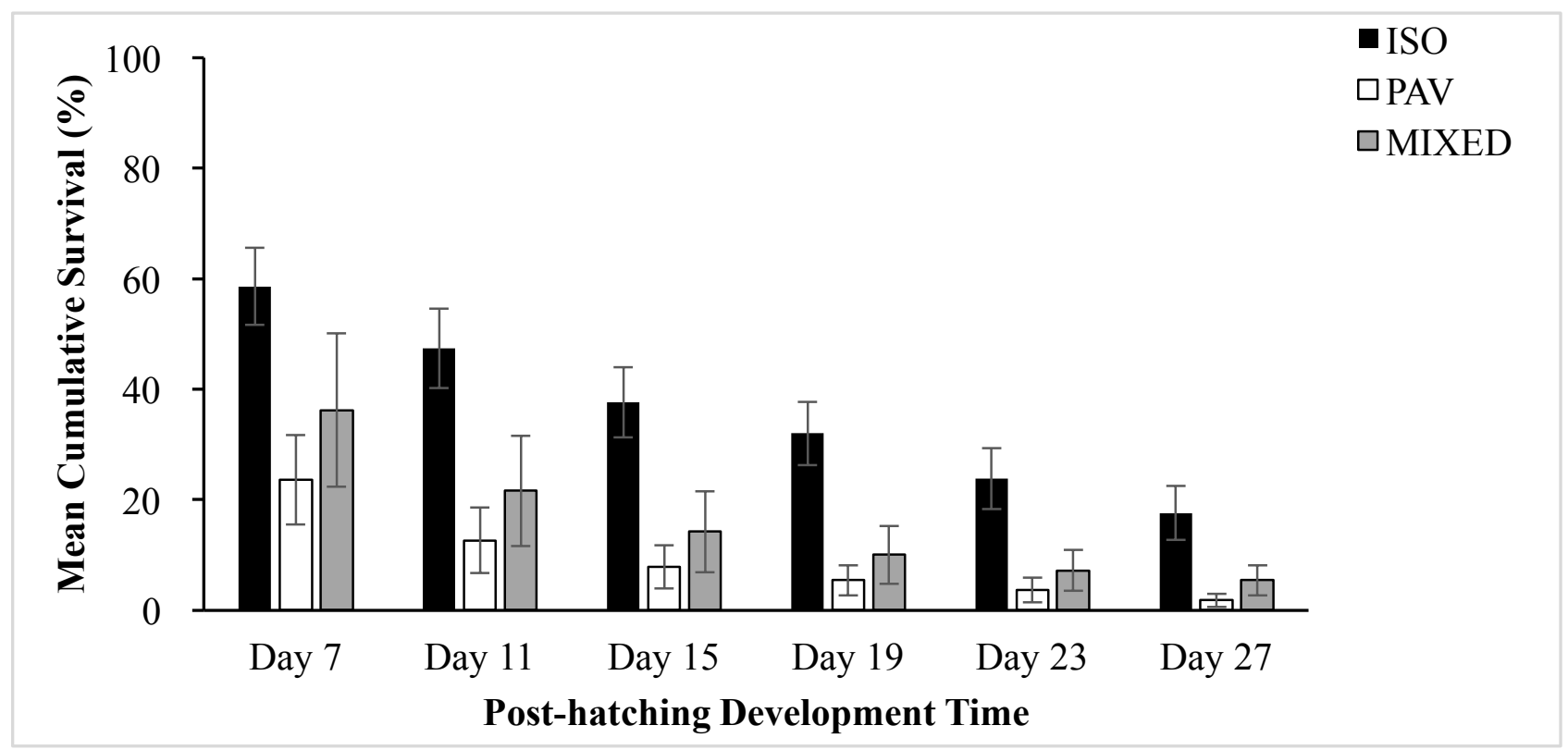

Figure 2.4 Mean cumulative survival percentage of $S$. australis larvae when subjected to different algal diets over time $( \pm \mathrm{SE}), \mathrm{n}=5$ per treatment per PDT.

\subsubsection{Experiment 2: Food Concentration}

\subsubsection{Larval Growth}

Food concentration $\left.\left(\mathrm{F}_{2,49.124}\right)=12.810, \mathrm{p}<0.001\right)$, and PDT $\left.\left(\mathrm{F}_{4,48.458}\right)=7.828, \mathrm{p}<0.001\right)$ both had a significant effect on larval growth, and there was a significant interaction between these two factors $\left.\left(\mathrm{F}_{7,48.201}\right)=2.706, \mathrm{p}=0.019\right)$. The interaction occurred because the effect of food concentration was small early in larval development, but became increasingly larger over time (Fig 2.5). Separate nested one-way ANOVAs were conducted to further explore differences in food concentration on each 
sample date. Results showed that there were significant differences in food concentration on all days except Day 27 (Table 2.2). This is most likely the cause of all low treatments having ended before the trial was completed; at this stage, statistics show there was no significant difference in larval growth between the medium and high treatments. Although it appears in Fig 2.5 that there is a significant difference, with medium treatments showing average larval sizes of $\sim 220 \mu \mathrm{m}$ and high treatments showing average larval sizes of $\sim 290 \mu \mathrm{m}$, the majority of the medium treatments had ended due to low survival, whilst all the high treatments were still active. Of further interest is the observation that larvae in low food treatments essentially did not grow over the 22 days before this treatment was terminated due to low survival. A summary of these results is shown in Table 2.2.

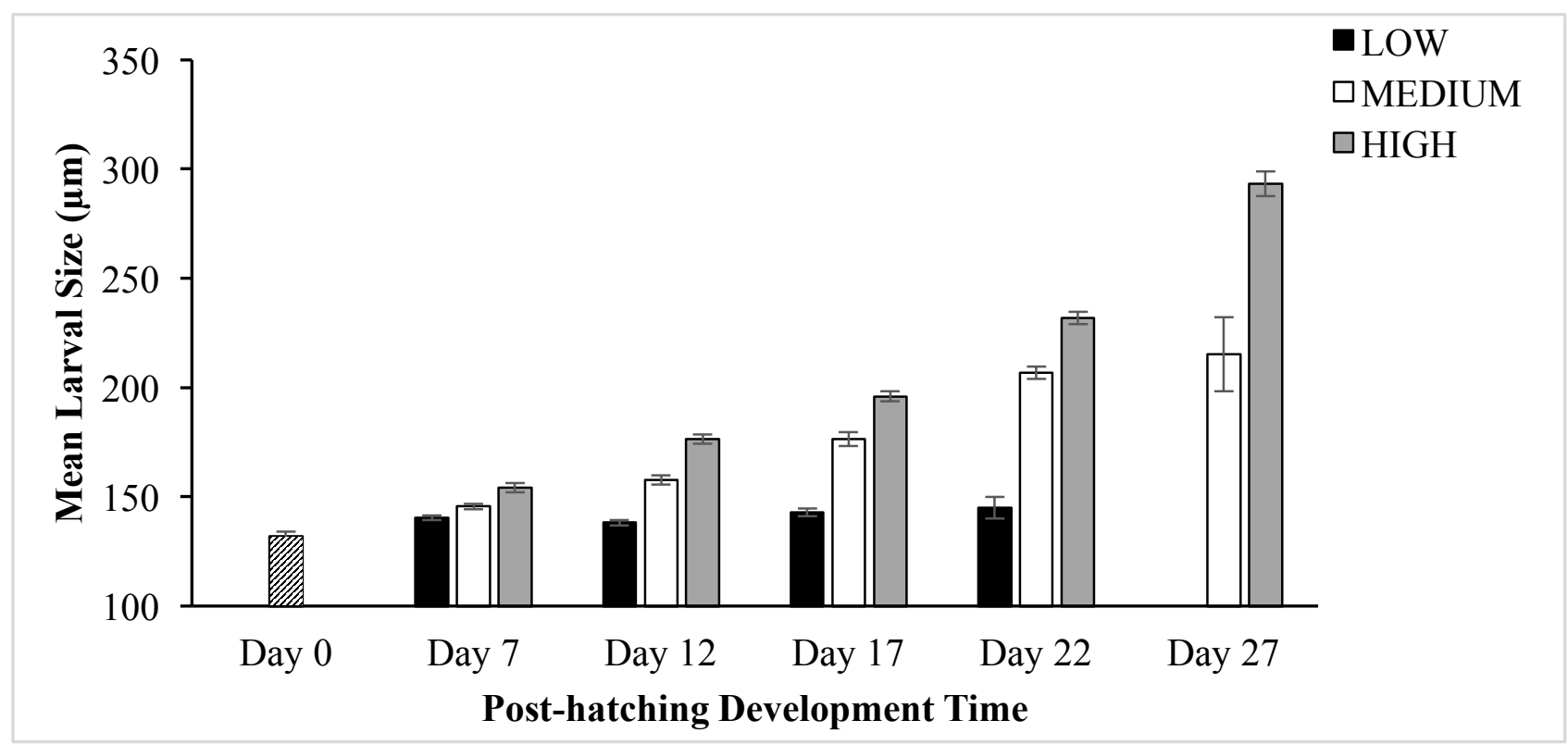

Figure 2.5 Mean S. australis larval size $(\mu \mathrm{m})$ when subjected to different I. galbana food concentrations over time $( \pm \mathrm{SE}), \mathrm{n}=10$ for each available replicate per treatment per PDT. Day 0 represents mean larval hatching sizes. 
Table 2.2 Summary of nested one-way ANOVA results examining effects of I. galbana food concentration on S. australis larval growth on each post-hatching development date. Bold p-values indicate significance at a level of 0.05

\begin{tabular}{|l|r|r|r|}
\hline \multicolumn{1}{|c|}{ PDT } & F & df & \multicolumn{1}{c|}{ p } \\
\hline 7 & 4.133 & 2,12 & $\mathbf{0 . 0 4 3}$ \\
\hline 12 & 16.649 & $2,12.3$ & $<\mathbf{0 . 0 0 0 1}$ \\
\hline 17 & 12.779 & $2,9.4$ & $\mathbf{0 . 0 0 2}$ \\
\hline 22 & 10.963 & $2,8.8$ & $\mathbf{0 . 0 0 4}$ \\
\hline 27 & 4.555 & 1,7 & 0.070 \\
\hline
\end{tabular}

\subsubsection{Larval Survival}

Food concentration had a significant effect on larval survival $\left.\left(\mathrm{F}_{2,60}\right)=40.87, \mathrm{p}=<0.001\right)$, whereas PDT did not have a significant effect $\left.\left(\mathrm{F}_{4,60}\right)=2.234, \mathrm{p}=0.076\right)$, yet there was a significant interaction between these two factors $\left.\left(\mathrm{F}_{8,60}\right)=2.278, \mathrm{p}=0.034\right)$. Upon closer examination, high food treatments resulted in the highest larval survival, especially early on in larval development, whereas low food treatments resulted in the lowest larval survival, and larvae in these treatments did not survive past 22 days post-hatching (Fig. 2.6). Larvae in medium food treatments exhibited intermediate survival rates. Survival to Day 27 in this experimental trial of larvae fed a high concentration of ISO was nearly three times higher than the first trial.

For both experiments, trials were terminated at 27 days, as high larval mortalities occurred in at least one of the treatments in each case, making further treatment comparisons not possible. However, at 27 days in the second trial, there still remained high larval survival in the high food treatments. Therefore, this treatment was maintained and these larvae continued to be observed for another week. Once larvae reached a shell length of $350 \mu \mathrm{m}$, after approximately 30 days PDT, growth rates plateaued and larvae began to exhibit signs of competence (i.e. active use of the foot, searching/crawling behaviour), a stage, to our knowledge, that has never been reached for this genus. 


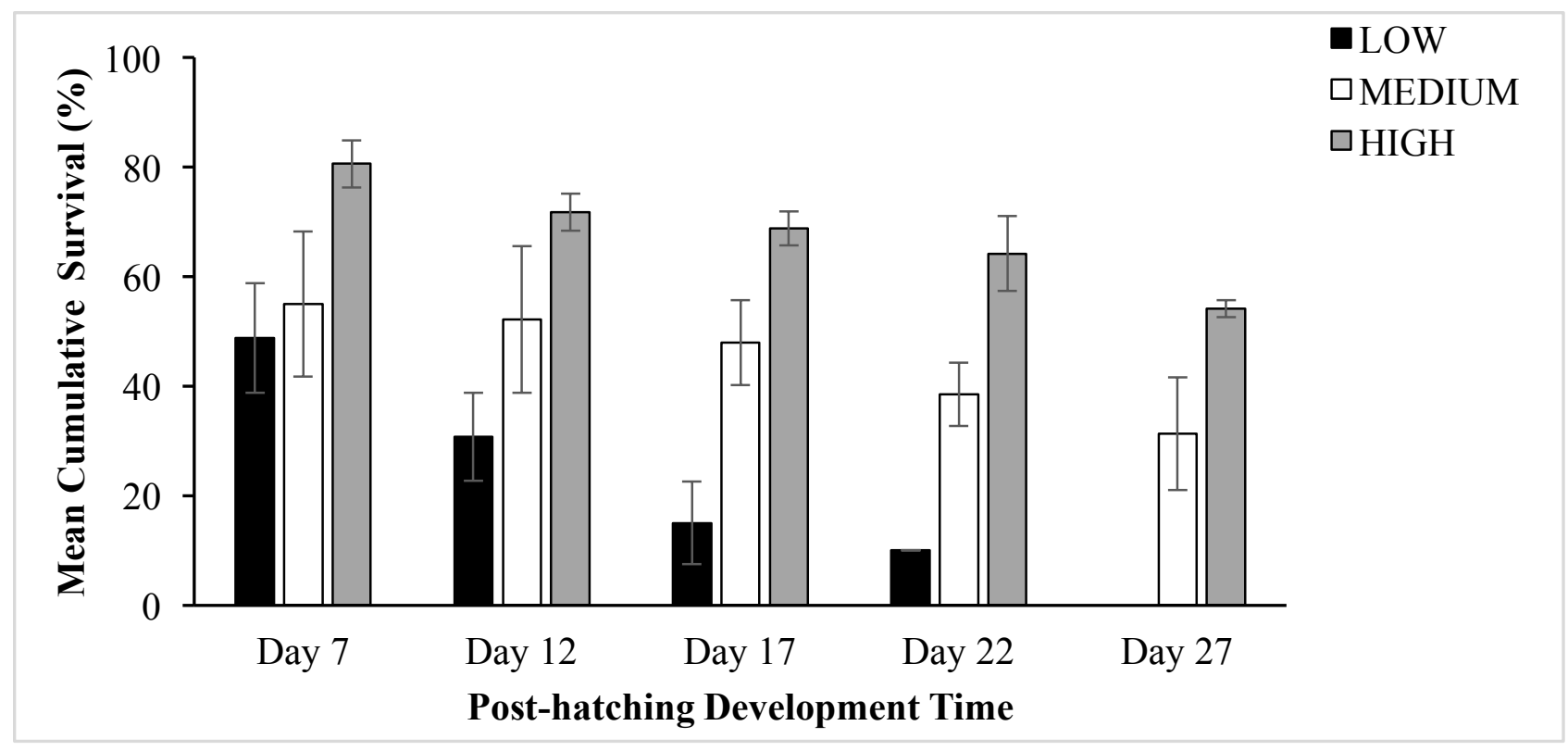

Figure 2.6 Mean cumulative survival percentage of $S$. australis larvae when subjected to different $I$. galbana food concentrations over time $( \pm \mathrm{SE}), \mathrm{n}=5$ replicates per treatment per PDT (excluding medium treatments on Day 27, where $\mathrm{n}=3$ ).

\subsection{DISCUSSION}

In this study, algal composition did not have much of an overall effect on the growth rate of $S$. australis larvae, except for in the first two weeks of development after hatching. This is important to consider as, for this species in the natural environment, it could be the first two weeks that require maximal nutrient assimilation for the development of crucial organs. In nature, developmental constraints need to be overcome as soon as possible (Paulay et al., 1985), to avoid prolonged exposure to environmental factors that can increase larval mortality (Thorson, 1950). If larvae experience good food quality and quantity during early development, they obtain the required nutrients, and therefore energy, to develop quickly (Bos et al., 2006; Przeslawski et al., 2012). If larvae are unable to obtain optimum nutritional requirements during this stage, consequential effects can extend past decreased growth rates and prolonged development (Qian \& Chia, 1991; Eckert, 1995; Basch \& Pearse, 1996) to a smaller size or lower energy content at (Qian \& Chia, 1993; Eckert, 1995), or at the onset of metamorphosis (Pechenik et al., 1996a), as well as an overall decrease in metamorphic success (McEdward \& Qian, 2001). A swift growth rate can also be more beneficial for outgrowing the size specificities of predators, as well as increasing the rate of developmental complexity of the organism, potentially enhancing individual sturdiness against environmental extremes. 
In contrast to growth, algal composition had a significant impact on the survival rates of $S$. australis larvae, in which the unialgal Isochrysis galbana diet resulted in the highest larval survival. This was surprising; the mixed diet composition was expected to exhibit the highest survival rates, as it is often considered to be more beneficial for larval development by providing a wider range of nutrients (Helm, 1977; Brown, 2002; Puello-Cruz et al., 2009; Guedes \& Malcata, 2012). However, one possible contributing factor is that the quality of Pavlova lutheri appeared to decline during the trial, which could have impaired the results. It should therefore be noted that, although S. australis larvae survived best with a unialgal I. galbana diet, a mixed diet with different algae, or a different culture, may have had more successful results and should not be disregarded.

Planktotrophic larvae differ in their nutritional requirements, hence there is an increasing number of researchers examining the biochemical composition of phytoplankton for their nutritionally important components (Thompson \& Harrison, 1992). The nutritional value of an algal species depends upon (1) the ability of the larva to ingest, as well as digest, it, and (2) the ability of the phytoplankton species to provide the larva with nutrients essential for growth and development (Davis \& Guillard, 1958; Pechenik \& Fisher, 1979). The factors influencing the nutritional value of an algal species include the biochemical composition and texture of the cell wall, cell size, digestibility, toxicity, cell motility, and age/growth stage of the culture (Pilkington \& Fretter, 1970; Strathmann, 1987; Brown, 2002; Guedes \& Malcata, 2012). The unialgal I. galbana diet was shown to be an excellent food for S. australis larvae, suggesting that the cell size $(5-6 \mu \mathrm{m})$, age (young i.e. less than 4 weeks old and rapidly growing), cell motility (most active at the chosen temperature; (Strathmann, 1987)), and nutrient composition of this algal species is sufficient in maximising larval growth and development in this species. I.galbana has also been shown to benefit the growth of other invertebrate larvae; Pechenik \& Fisher (1979) found that larvae of Nassarius obsoletus grew well on the small cells of Isochrysis galbana, and were able to be reared to metamorphosis. However, they exhibited higher growth rates on a diet of the same cell-sized diatom Thalassiosira pseudonana $(5-8 \mu \mathrm{m})$ at the same concentration, with daily observations showing that larvae were ingesting the latter algal species at a faster rate. This suggests that, although I. galbana is a good food for N. obsoletus, a diet of $T$. pseudonana better meets the nutritional requirements of this species. Larvae of the bivalve Ostrea edulis (Walne, 1963), and the barnacle Chthamalus stellatus (Moyse, 1963), can also be reared to metamorphosis on a diet of I. galbana, however larvae of the barnacle Balanus balanoides (Moyse, 1963), the copepod Tigriopus japonicus (Shiraishi \& Provasoli, 1959), and a variety of larval sea urchins (Hinegardner, 1969) do poorly, indicating a failure of this algae to supply some essential micronutrient to these organisms, as well as there may be potential for these species to handle small cells less efficiently than larger cells (Walne, 1956). Hence, to have a clear understanding of 
planktotrophic larval nutrition requires knowledge of both the nutritional requirements of the target organism and the biochemical composition of the food.

In regards to Pavlova lutheri, it has been shown to be a good food for mollusc veligers (Davis \& Guillard, 1958; Loosanoff \& Davis, 1963; Persoone \& Claus, 1980; Brown, 2002), especially when mixed with other algal species such as I. galbana (Delaunay et al., 1993; O'Connor \& Heasman, 1997; Guedes \& Malcata, 2012), however, studies of it being a good nutritional unialgal diet for gastropod veligers specifically, are scarce. However, Klinzing \& Pechenik (2000) found that, over a wide range of phytoplankton concentrations, larvae of the limpet Crepidula fornicata grew substantially more quickly (40-60\% faster) on a unialgal diet of I. galbana than on a unialgal diet of P. lutheri, where they grew at intermediate rates. Padilla et al. (2014) found that, when larvae of $C$. fornicata were raised on unialgal diets of $P$. lutheri and I. galbana, there were no significant differences in larval survivorship between the two, yet larval growth rates were not mentioned. Fritter \& Montgomery (1968) mention that anexic $P$. lutheri cultures (i.e. entirely free of contaminating organisms) do not support the development of prosobranch veligers, possibly because of an accumulation of products normally broken down by bacteria. Although these few studies suggest that $P$. lutheri is a poor food for gastropod veligers, more research is required, on more gastropod species, to further confirm this.

Food concentration had a strong effect on both the growth and survival rates of $S$. australis larvae, with high food treatments $\left(2.0 \times 10^{5}\right.$ cells $\left./ \mathrm{mL}\right)$ resulting in larger, faster larval growth rates and higher survival rates compared to low food treatments $\left(1.0 \times 10^{3}\right.$ cells $\left./ \mathrm{mL}\right)$, similar to results observed in other larval studies (Pechenik et al., 1990; Qian \& Chia, 1993; Klinzing \& Pechenik, 2000; Vos et al., 2000). Other larval culturing studies incorporating a unialgal I. galbana diet have described success with different feeding concentrations; Pechenik \& Fisher (1979) cultured larvae of Nassarius obsoletus at a concentration of $<2.6 \times 10^{6}$ cells/mL; Switzer-Dunlap et al. (1977) and Plaut et al. (1995) successfully cultured aplysiid larvae at concentrations of $10^{4}$ cells/mL; Puello-Cruz et al. (2009) cultured the calanoid copepod Pseudodiaptomus euryhalimus at a concentration of $3.2 \times 10^{5}$ cells/mL; Gruffyyd \& Beaumont (1972) reared larvae of the scallop Pecten maximus at concentrations of $5.0 \times 10^{4}$, and; Aranda-Burgos et al. (2014) cultured larvae of the bivalve Ruditapes decussatus at a concentration of $4.0 \times 10^{4}$ cells $/ \mathrm{mL}$. This shows that, even on the same feeding diet, varying planktotrophic larvae exhibit a range in their food level requirements. It should also be emphasised that, because these results are based on a unialgal diet, they may not be completely analogous to food concentrations/compositions in the field, as well as the laboratory feeding situation may influence feeding rates differently to what occurs in nature. Larvae in these studies, including this current study, 
may have been influenced by other factors such as culture set up, feeding methods, feeding intervals, and larval densities (see Capo et al., 2009; Przeslawski et al., 2012).

\subsection{CONCLUSION}

Larvae are plastic in their responses to different algal compositions and concentrations. Whether an algal species is a suitable food to support optimal rates of growth and differentiation for a larva will be highly specific for that combination of algal and larval species. Here, Siphonaria australis larvae were shown to respond best to a unialgal Isochrysis galbana diet at a high feeding concentration, where larval growth and survival rates were much greater compared to other food treatments. Further, this study identified the optimal microalgal diet for culturing these larvae to competence, allowing for exploration into settlement cues to induce metamorphosis, which is focused on in the next chapter. 


\section{CHAPTER 3. Determining the required cues to induce settlement and metamorphosis in Siphonaria australis}

\subsection{ABSTRACT}

The successful settlement of benthic marine invertebrates involve complex processes determined by the interaction of biotic and abiotic factors operating at varying temporal and spatial scales. To our current knowledge no attempts have been made to decipher which settlement cues are required to induce larval settlement and metamorphosis for the genus Siphonaria, in the field or in laboratory conditions. To address this gap in knowledge, S. australis larvae were raised in the optimum feeding diet established from the previous chapter, i.e. a unialgal Isochrysis galbana diet at a high concentration $(20,000$ cells $/ \mathrm{mL})$. Once larvae began to show signs of competence, they were exposed to a range of settlement cues, chosen for their success in other marine invertebrate settlement studies and preliminary studies on this species. These included: live adults in filtered seawater (FSW), adultconditioned FSW, rocks in adult-conditioned FSW, rocks in FSW, and crustose coralline algal covered rocks in FSW. Each settlement cue treatment had three replicate dishes, and 20 larvae were added to each dish. Larvae were left in the dishes, which were all gently aerated, for three days, after which they were checked for successful settlement and metamorphosis (i.e. settlement to the substrate and resorption/loss of velum (Bonar \& Hadfield, 1974)). S. australis larvae exclusively metamorphosed in dishes with live adults present (17\% success). These results provide evidence that, for this species, a conspecific cue is very important in the substrate selection of these larvae at competence.

\subsection{INTRODUCTION}

The majority of benthic marine invertebrates have a dispersive larval stage in their life histories, where larvae spend some time developing in the plankton before becoming competent to settle and metamorphosing back onto the benthos (Thorson, 1950; Pechenik, 1979; Hadfield \& Paul, 2001). Understanding the abiotic and biotic factors which can influence settlement and metamorphosis of marine invertebrate larvae is an important component of such disparate fields as developmental biology, marine community ecology, and aquaculture (Hadfield \& Paul, 2001). 
Settlement and metamorphosis are two coupled events in a larval life cycle. Here, we will apply Rodriguez et al's (1993) definition of settlement, in which they described it as a process with two stages; a "behavioural searching phase", followed by "a phase of permanent residence or attachment to the substratum, which triggers metamorphosis". For metamorphosis, we will apply Hadfield \& Paul's (2001) definition where "metamorphosis includes loss of larva-specific organs - typically those used in planktonic swimming - and emergence of juvenile/adult-specific structures".

Settlement and metamorphosis can be considered the most complex period in the life history of benthic marine invertebrate larvae (Slattery, 1997). The majority of larvae are influenced by distinct chemical and physical cues, which ensure settlement and metamorphosis to appropriate sites for juvenile growth and eventual recruitment back into adult populations (Crisp, 1974; Pawlik, 1992; McEdward, 1995). Competent larvae (i.e. those that are physiologically capable of responding to settlement cues) will retain morphological features required for planktonic life until the appropriate stimulus is found for settlement and metamorphosis and, in the absence of this, many larvae can delay their settlement (Thorson, 1950; Highsmith \& Emlet, 1986; Coon et al., 1990; Jensen \& Morse, 1990; Rodriguez et al., 1993). Although this delay increases the chance of larvae finding an optimum habitat for successful settlement, metamorphic growth, and reproduction (Pechenik, 1990), it also increases time in the plankton, which alleviates exposure to predation risks and offshore currents (Thorson, 1950). Hence, for selection and attachment to a substratum to then be followed by metamorphosis, depends on biotic and abiotic cues, and on larval behaviour and responses (Rodriguez et al., 1993).

Considerable experimental evidence suggests that chemical cues are very significant when it comes to substrate selection by marine invertebrate larvae. Although it has been shown that physical factors such as substratum contouring, structural texture/complexity, and shear/slope angle can influence settlement success (see: Crisp \& Barnes, 1954; Crisp, 1961; Carleton \& Sammarco, 1987; Walters \& Wethey, 1996), it applies mainly to sessile marine invertebrates. Chemical settlement cues originate from, or are associated with, a variety of sources in the marine environment and hold great ecological importance (Hadfield \& Paul, 2001). Such cues may be (1) waterborne or adsorbed to surfaces associated with conspecific individuals (Highsmith, 1982; Jensen \& Morse, 1984; Burke, 1986; Pawlik, 1992), (2) specific prey species (Barnes \& Gonor, 1973; Sebens, 1983; Morse \& Morse, 1984), or (3) microbial films (Cameron \& Hinegardner, 1974; Kirchman et al., 1981). Chemical cues regulate critical aspects of larval behaviour during the competence and metamorphic period, with chemically-mediated interactions strongly affecting population structure, community organisation, and ecosystem function (Hay, 2009). Deciphering the mechanisms by which environmental chemical 
signals mediate various life-history processes can lead to important insights about the forces driving the ecology and evolution of marine systems (Zimmer \& Butman, 2000; Hay, 2009).

Settlement induced by conspecific adults has been described in several marine invertebrate species, including polychaetes (Jensen \& Morse, 1984; Pawlik, 1992), echinoids (Highsmith, 1982), abalone (Seki \& Kan-No, 1981; Slattery, 1992), barnacles (Knight-Jones, 1953; Raimondi, 1988), and oysters (Hidu et al., 1979). The existence of such larval settlement inducers has great ecological importance, as it can account for the aggregated distributions of many coastal marine invertebrates (Rodriguez et al., 1993), as well as increases the probability of fertilisation (Pearce \& Arch, 1969).

In some benthic marine invertebrate larvae, settlement is induced by potential prey species of the juveniles or adults (Pawlik \& Hadfield, 1990; Hadfield \& Paul, 2001). For herbivorous species especially, a common settlement inducer is crustose coralline red algae, which has been shown to induce larval settlement in abalone (Morse et al., 1980; Morse \& Morse, 1984; Shepherd \& Turner, 1985; Morse, 1990), chitons (Barnes \& Gonor, 1973), sea urchins (Cameron \& Hinegardner, 1974; Rowley, 1989; Pearce \& Scheibling, 1990), and limpets (Steneck, 1982). There is also evidence that water-soluble extracts of crustose coralline algae can induce settlement (Hadfield \& Paul, 2001; Ritson-Williams et al., 2009).

Microbial films have long been recognised as necessary for inducing the settlement of some marine invertebrate larvae (Cameron \& Hinegardner, 1974; Parsons et al., 1993; Wieczorek \& Todd, 1997) whilst for others, it facilitates settlement by enhancing the acceptability of surfaces (Pawlik, 1992; Johnson et al., 1997). Biofilm appears to be the settlement cue of choice most notably for the fouling community of sessile invertebrates (Scheltema, 1974; Hadfield \& Paul, 2001).

In this chapter, the aim was to determine which cue(s) induced metamorphosis in the larvae of Siphonaria australis, thereby completing the successful settlement and culture of this species in laboratory conditions. 


\subsection{METHODS}

This experiment was conducted from January to February 2016 and was designed to determine which cues induced settlement and metamorphosis in larvae of S. australis.

Five freshly deposited egg masses ( $<24$ hours post-spawning) were collected from the adult tank and raised until hatching in a temperature-controlled lab as described in Chapter 2. Fifteen $500 \mathrm{~mL}$ beakers were filled with FSW to which 250 larvae were added, with the overall aim to have as many survivors as possible for settlement trials. Beakers were hand-stirred daily. Feeding occurred every three days, consisting of a unialgal diet of Isochrysis galbana at a high concentration $(20,000$ cells $/ \mathrm{mL})$. Water changes were done every five days. To assess larval growth rate, ten larvae per beaker were measured with every water change. Signs of larval competence were observed when larvae reached a shell length of approximately $350 \mu \mathrm{m}$ (Fig 3.1). At this stage, they had a large and active foot, exhibited crawling behaviour, and showed signs of searching behaviour on the bottom of the dishes. These are similar to signs of competence in other gastropod larvae (e.g. Bonar \& Hadfield, 1974; SwitzerDunlap \& Hadfield, 1977).

As larvae began to show signs of competence, settlement trials were prepared using cues in small glass bowls of approximately 300mL FSW. The settlement cues chosen were: (1) five live adults in adult-conditioned FSW; (2) adult-conditioned FSW only; (3) small rocks glued on glass slides in adult-conditioned FSW; (4) small rocks glued on glass slides in FSW; and (5) small crustose coralline rocks in crustose-coralline conditioned FSW. There were three replicate bowls for each settlement cue. Unfortunately there were not enough larval survivors to include a simple FSW no-cue control, but from preliminary trials it was confirmed that larvae would not spontaneously settle and metamorphose in FSW alone.

Trials involving "conditioned" water were prepared three days beforehand. For adult-conditioned water, five adults were placed in each replicate glass bowl of FSW, with gentle bubbling. Bowls were covered in mesh to prevent adult escape. For crustose coralline algae-conditioned water, small rock pieces covered in crustose coralline algae, that had been collected fresh from the field and gently scrubbed to remove macro-organisms, were placed in glass bowls and left to "soak" in FSW for three days.

When larvae had reached average shell sizes of $350 \mu \mathrm{m}, 20$ larvae were pipetted into each bowl. Settlement success was recorded as the number of individual larvae having exhibited metamorphosis 
(i.e. loss of the larval velum) after three days, although progress was checked daily. At three days, all bowls were checked thoroughly. This involved finding all 20 larvae and observing them carefully. Individual larvae were assessed for survival and, for those still alive, these were checked for whether they had successfully metamorphosed or not.

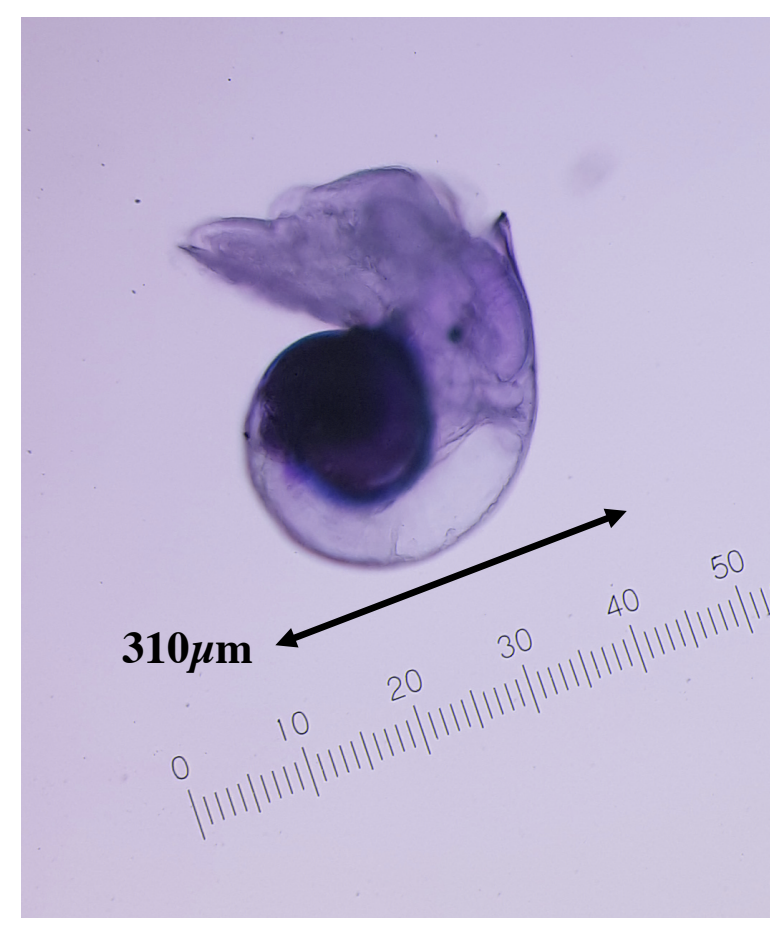

Figure 3.1 Shell length of an S. australis larvae nearing competence, measured beneath a compound microscope (100x magnification). Note the display of the foot and the eyespot. Photo taken by: S. Marinus, 2016.

\subsection{RESULTS}

Larvae exhibited successful metamorphosis within 24-48 hours of being in the presence of the correct inducer. Out of all the trials conducted, larvae only successfully settled and metamorphosed (Fig. 3.2) in one cue; that of the live adults in adult-conditioned FSW. Here, 10/60 (17\%) larvae had successfully settled either onto the shells of the adults (Fig 3.3) or on the bottom of the glass dish. 


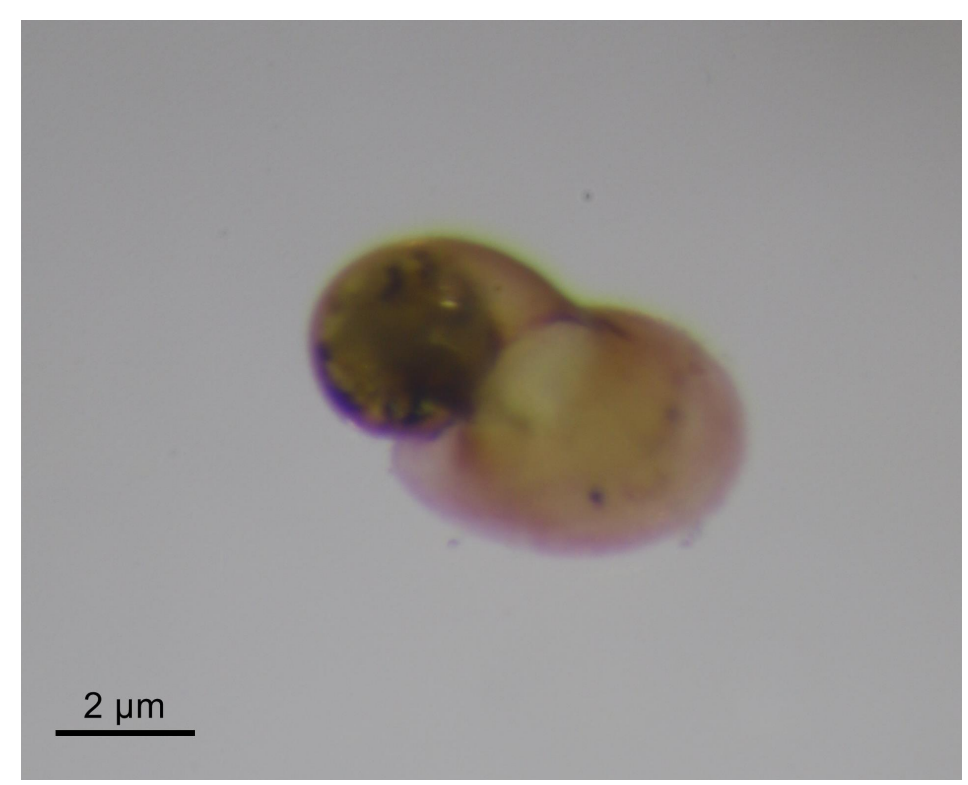

Figure 3.2 Newly settled and metamorphosed $S$. australis juvenile at 4.4x magnification, beneath a dissecting microscope. Photo taken by: S. Marinus, 2015/2016.

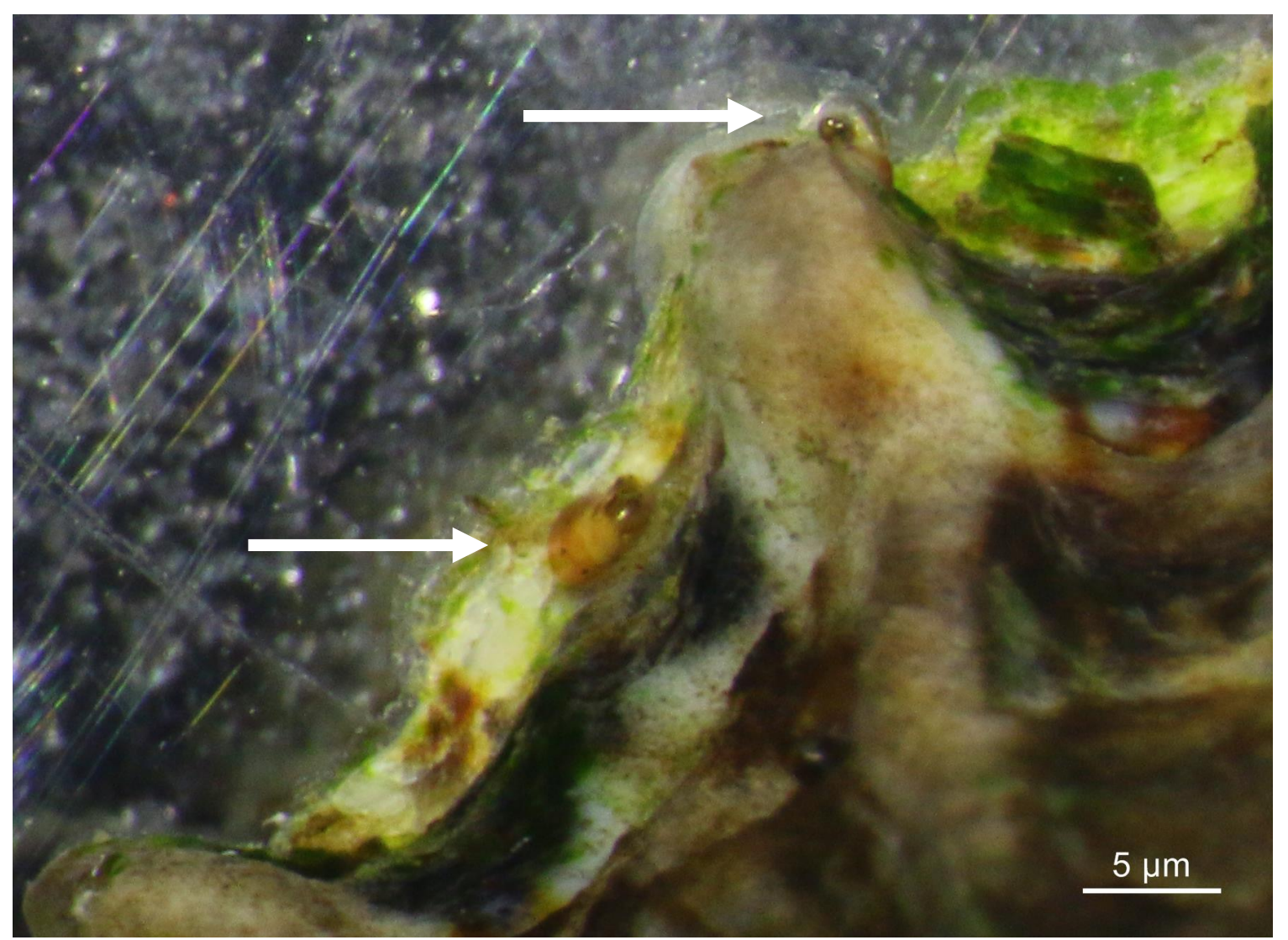

Figure 3.3 Newly settled and metamorphosed S. australis juveniles (arrows) on the shell of an adult, beneath a dissecting microscope at 1.1x magnification. Photo taken by: S. Marinus, 2016. 


\subsection{DISCUSSION}

Under optimum laboratory conditions identified in the previous chapter, and at a temperature of $17^{\circ} \mathrm{C}$ $\pm 1.6^{\circ} \mathrm{C}$, veliger larvae of Siphonaria australis begin to exhibit signs of competence after approximately a month from their emergence from the egg mass, and will settle and metamorphose, within a short time frame, when live adults are in the vicinity. This demonstrates that the presence of a conspecific cue is most likely necessary for inducing the settlement and metamorphosis of $S$. australis larvae.

The response of S. australis larvae to a conspecific cue resembles that of several hard-substrate species that exhibit gregarious settlement in the field. Gregarious settlement occurs when larvae choose to settle in response to the presence of adults, juveniles, or recent recruits of the same species (Hadfield \& Paul, 2001). However, S. australis are not naturally gregarious in their adult distribution in the field. It can be argued that, just because a larva exhibits induced settlement in the presence of a conspecific cue, this does not necessarily mean that larvae will preferentially settle in such areas, and form gregarious community structures. Here, S. australis may choose to settle near adult conspecifics, as the presence of such cues likely indicates a suitable habitat (i.e. including an appropriate food source and potentially, reduced predation pressure) (Slattery, 1997).

Larval/juvenile survivorship may then be higher early on in post-settlement, and migration may then occur once individuals are more resilient to external factors.

Particular environmental stimuli may alter the timing of metamorphosis, and although it is possible that the duration of this experiment was not long enough to test this theory, it could partially explain what was observed. Larvae were shown to metamorphose, within a very short time frame, in treatments that contained live adults (i.e. a conspecific cue), with no particular substrate present except that of the adult shells. Although larvae showed no signs of metamorphosis in other treatments containing conspecific cues, perhaps metamorphosis would have been observed if the duration of treatments had been extended, as larvae may have been exhibiting variation in the timing of attaining competence. Aside from a genetic aspect, suggestions for variation in metamorphic timing can also include (1) the need for another environmental stimulus alongside the conspecific cue (Hadfield \& Paul, 2001), and (2) larval age (Plaut et al., 1995). If particular substrata are a necessary stimulus for S. australis, it could explain why no larvae settled on the small rock pieces glued to glass slides, even in the presence of a conspecific cue, as these rock pieces may not have resembled those in the field. It may also explain why larvae did not metamorphose in treatments containing only adult-conditioned FSW without a substrate present. It is possible that if a utilised substrata, that had better resembled that of the natural habitat of this species, had been present, the effect on the duration of metamorphosis 
may have been the same or stronger than the live adult cue (Gebauer et al., 1998). Although importance of physical characteristics of the substratum generally applies more strongly to sessile organisms, the rock substratum used here may not have been meeting some metamorphic requirement in these larvae. In Gebauer \& Anger's (1998) study of Chasmagnathus granulata megalopae, metamorphosis occurred earlier in the presence of a muddy substratum synergised with the presence of chemical cues from adult conspecifics, compared to other substrata or seawater alone, and that the strongest stimulus was provided by a combination of these two factors. In the absence of these stimuli together, the majority of larvae delayed their metamorphosis by a maximum of $29 \%$. These results indicate that $C$. granulata larvae have the ability to alter the timing of their metamorphosis, depending on the presence or absence of habitat-related stimuli, even with a conspecific cue present. Similar results have also been reported for other soft-sediment dwelling organisms (Suer \& Phillips, 1983; O'Connor, 1991), and the same theory could be applied to S. australis. Here, larvae were shown to settle on adult shells, which could represent some need for a particular substrate to be present along with the live adult cue. In the field, adults are mobile, meaning they could be adsorbing chemical cues to the substrate surface as they move, leading to preferential larval settlement near, but not explicitly aggregated to, adult populations. It should also be noted that, because some larvae metamorphosed on the bottom of glass dishes in the live adult cue treatment, suggesting that a substrate is not required, this does not necessarily mean this was where metamorphosis was initiated.

Research by Weber \& Epifanio (1996) showed that stimuli related to the preferred adult substrata, as well as the presence of adult conspecifics, induced metamorphosis in competent megalopae of Panopeus herbstii. This, alongside Gebauer \& Anger's (1998) results, can lead to further speculation as to why larvae did not settle on the crustose-coralline algae (CCA) treatments. If more larvae had been available, it would have been interesting to expose them to a cue of CCA + live adults and observe whether larvae would have metamorphosed with these two factors present. If metamorphosis occurred, this would provide evidence that a substrate obtained from the field, which S. australis adults are known to actively graze upon, is necessary, alongside the presence of adults, to induce metamorphosis.

In another interesting study, Zhao \& Qian (2002) discovered that larvae of the slipper limpet Crepidula onyx exhibited a higher percentage of settlement in treatments with adults present, compared to treatments that only contained adult-conditioned seawater. They suggest that the presence of adults in the dish mimicked a more natural environment for competent larvae compared with exposure to adult-conditioned FSW alone; larvae would detect the waterborne conspecific chemical cue first, leading to positive downward swimming, thereby increasing chances to make 
contact with the substrate and expose themselves to higher concentrations of waterborne conspecific cues. This would eventually lead to the enhanced larval settlement pattern on or near the conspecific adults. They also mention the percentage of larval metamorphosis in response to the adult-conditioned water varied among experiments, and that this may have been the cause of varying physiological situations in the adults used for preparing the conditioned sea water, potentially resulting in different concentrations of potential active cues. They also speculate that the different settlement rates observed amongst experiments may also have been due to varying larval sensitivity levels in response to cues, as different batches of larval cultures were used during their experiments.

These results can be analogous to what was observed in this study. Although no larvae were shown to metamorphose in the adult-conditioned FSW treatments, reasoning could relate to the physiological conditions of the adults used to condition the water, as well as the water may not have been conditioned enough for larvae to detect the cue. In the live adult treatments, the conspecific cue would be more concentrated. Varying larval sensitivity levels to settlement cues could also be a possibility here, as this can be linked with genetic variability amongst larval individuals.

The influence of larval age at competence could also be considered a factor in larval settlement (Plaut et al., 1995). Satuito et al. (1997) studied the settlement responses of the barnacle Balanus amphitrite to various factors, and found that responses varied with age. Older (1-3 days old at competence) cyprids were more readily responsive to settlement cues than newly-competent ones. Other studies have also shown that older cyprids generally settle at higher rates than newly moulted ones (Rittschof et al., 1984; Crisp, 1988; Pechenik et al., 1993). In the case of S. australis, larvae were exposed to settlement cues once shell length averages were $350 \mu \mathrm{m}$; because there is variability amongst individuals, some larvae may have reached $350 \mu \mathrm{m}$, and thereby competence, earlier than others, suggesting these larvae were "older" and more readily responsive to settlement cues. This could explain why not all (live) larvae exhibited metamorphosis in the live adult treatments. Age dependence in response to settlement inducers has also been reported in a variety of other marine invertebrate larvae e.g. in the abalone Haliotis rufescens (Morse et al., 1979; Barlow, 1990); the oyster Crassostrea gigas (Coon et al., 1990); and the mussel Mytilus edulis (Eyster \& Pechenik, 1988).

Although we can confidently say that a conspecific cue is required to successfully induce settlement and metamorphosis in S. australis larvae, many other factors could also play a role. To test for these factors would require higher larval numbers at competence. For this trial, survival number was not as high as we had hoped, yet the end goal was ultimately achieved. 


\subsection{CONCLUSION}

A major gap in the knowledge of the life history of Siphonaria australis has been filled and we can now work towards obtaining a greater understanding of the development and ecological processes behind the larval settlement and metamorphosis of the Siphonaria genus. This culturing method can be applied to more extensive research regarding this species, which will be discussed in the following chapter. 


\section{CHAPTER 4. General Discussion}

\subsection{Summary of Results}

The present study reports on the development of simple, reliable techniques for the successful laboratory culture of the pulmonate limpet Siphonaria australis from larval hatching through to settlement and metamorphosis. This now allows for further investigation into the larval biology, metamorphosis, and early juvenile development of this particular species.

Laboratory rearing studies on the larvae of benthic marine invertebrates are important in providing information on the development of marine species, particularly those with complex life cycles. In relation to their intertidal existence, gastropods of the genus Siphonaria have been well studied in aspects of their physiology, behaviour, ecology, and reproduction (reviewed by Hodgson, 1999). However, to our current knowledge, there are no cases where the planktonic larvae have been successfully reared in the laboratory from hatching through to metamorphosis. This leaves a crucial gap in our knowledge of the life history of Siphonariids.

The study of marine invertebrate nutrition is a subject of broad significance across a variety of fields. For larval culturing, it is important that not just food quantity but also quality are optimised for larvae to successfully reach competence, metamorphose, and settle, as an ideal food source leads to efficient rates in growth and survival (Perron, 1980). My experiments confirmed that a unialgal Isochrysis galbana diet at a high food concentration $(20,000$ cells $/ \mathrm{mL})$ was sufficient for formulating experimental conditions under which $S$. australis larvae would remain healthy and achieve competence. Indications of the sensitivity of these larvae to other laboratory culture conditions have been discussed (see Appendix).

In comparison to other gastropod larval rearing studies, similar results have been observed when using a unialgal I. galbana diet, with feeding concentrations varying amongst species; larvae of the mud snail Nassarius obsoletus at a concentration of <2.6 x $10^{6}$ cells $/ \mathrm{mL}$ (Pechenik \& Fisher, 1979); aplysiid larvae at concentrations of $10^{4}$ cells/mL (Switzer-Dunlap \& Hadfield, 1977; Plaut et al., 1995), and larvae of the gastropods Bittium alternatum, Crepidula fornicata, and Ilyanassa obsoleta at a concentration of $1.2 \times 10^{5}$ cells/mL (Pechenik, 1980), although C.fornicata has also been raised on a concentration of $18 \times 10^{4}$ cells/mL (Pechenik \& Lima, 1984; Pechenik \& Eyster, 1989). These 
studies suggest that, even on an identical feeding diet, planktotrophic gastropod larvae vary in their food level requirements across different species.

It is also important to familiarise with the biochemical composition of the algal species used in larval culturing studies, to understand how its nutritional value may be affecting the organism being cultured. Although there are marked differences in the compositions of the microalgal classes and species, protein is always the major organic constituent, followed by lipid, and then carbohydrate (Lavens \& Sorgeloos, 1996). Expressed as a percentage of dry weight, I. galbana contains 29\% protein, $12.9 \%$ carbohydrate, and $23 \%$ lipid, whilst $P$. lutheri contains $29 \%$ protein, $9 \%$ carbohydrate, and $12 \%$ lipid, both when harvested during the exponential growth phase (Lavens \& Sorgeloos, 1996). The content of PUFAs, in particular EPA, AA, and DHA, are also of major importance in the evaluation of the nutritional composition of an algal species when it is being used for feeding marine larvae. I. galbana and P. lutheri, are relatively rich in DHA (0.2 to $11 \%)$ and contain moderate to high percentages of EPA (7 to 34\%) (Lavens \& Sorgeloos, 1996; Payne \& Rippingale, 2000; Brown, 2002; Guedes \& Malcata, 2012). It is interesting to see that, although the biochemical composition between I. galbana and $P$. lutheri are quite similar, S. australis larvae responded differently to each unialgal diet. Although in treatments, food composition had no significant effect on larval growth, larvae exhibited lower survival in the PAV diet than in the ISO diet.

The biochemical composition of algae can be substantially altered by manipulating their culturing conditions, such as nutrient composition and concentration, light intensity, photoperiod or temperature, as well as age of the culture (i.e. older cultures are less nutritional) (Brown, 2002; Guedes \& Malcata, 2012). It can be speculated that, although both algal species were being cultured beneath identical conditions, the age or "growth phase" either species was undertaking may have influenced how S. australis larvae responded to the nutritional value of each diet. Hence, coinciding larval growth rate experiments with careful chemical analyses may substantially increase our understanding of nutritional requirements of planktotrophic larvae and the determinants of phytoplankton food value (Pechenik \& Fisher, 1979).

Many studies have discussed how food limitation or poor food quality results in detrimental effects on larval morphology, at the onset of metamorphosis, and at post-metamorphic stages (e.g. Pechenik et al., 1990; Qian \& Chia, 1993; Pechenik et al., 1996a; Wacker \& von Elert, 2002). During these experiments on the ideal feeding diet for S. australis, it was observed how substandard food composition and concentrations affected the larval stage; characteristics of slower growth rates and higher mortalities were the typical outcomes, as observed in many related studies (Pechenik et al., 
1990; Cruz-Rivera \& Hay, 2000; Vos et al., 2000) Although there is also evidence of developmental plasticity in gastropod veliger larvae under food limited conditions, where food-limited larvae have shown to grow larger velar lobes (i.e. the feeding structure) (Strathmann et al., 1993; see: Klinzing \& Pechenik, 2000), this aspect was not focused on here, yet may still have been applicable.

Marine invertebrate larvae eventually reach a point in development at which they will become competent to settle, and will then begin to assess the suitability of substrata for the oncoming dynamic transition to adulthood (Crisp, 1974; Doyle, 1975; Pawlik, 1992). Some marine invertebrate larvae select suitable adult habitats by metamorphosing in response to cues associated with certain environments (Burke, 1986). Although a variety of cues may be involved in inducing larvae to metamorphose, adsorbed and diffusible chemicals appear to be the cue of choice employed by a large number of marine invertebrates (Meadows \& Campbell, 1972; Crisp, 1974; reviewed by: Pawlik, 1992; and Hadfield \& Paul, 2001). Settlement in association with cues from conspecifics has been well documented in cnidarians (Williams 1976), polychaetes (Wilson, 1968; Jensen \& Morse, 1984; Pawlik, 1986), molluscs (Bayne, 1969; Slattery, 1992), crustaceans (Jensen, 1989), barnacles (Crisp \& Barnes, 1954; Raimondi, 1988), gastropods (Scheltema, 1961; Pechenik \& Gee, 1993; Stoner et al., 1996), and echinoderms (Highsmith, 1982; Pearce \& Scheibling, 1990). The importance of these settlement cues cannot be understated since the presence of conspecifics likely indicates a suitable habitat (i.e. including an appropriate food source, and potentially, reduced predation pressure).

For several marine invertebrate species, distribution within the intertidal is gregarious. It is suggested that this pattern of recruitment is achieved by larvae being induced to settle and metamorphose by chemical cues produced by conspecifics (Meadows \& Campbell, 1972; Scheltema, 1974; Burke, 1983), as they signal a beneficial settlement substrate. In this study, S. australis larvae, once having reached competence, were exposed to settlement cues focusing mainly on conspecific chemical cues due to results observed in preliminary studies. Larvae were shown to preferentially settle and metamorphose in the presence of conspecific cues with live adults present, which was confirmed by the loss of the larval velum and physical crawling on the foot (Bonar \& Hadfield, 1974). However, S. australis adults do not exhibit aggregative/gregarious behaviour in the field, but are mobile and dispersed randomly throughout the lower intertidal. Studies focusing on conspecific chemical cues inducing settlement and metamorphosis in mobile species have resulted in these organisms preferentially responding to chemical cues from biofilms or prey species (see Hadfield \& Paul, 2001), yet research exhibiting mobile gastropod larvae settling in response to conspecific cues without the following pattern of gregariousness are scarce. Because results observed in mobile marine invertebrate studies are not analogous to what was observed in this experiment, we can speculate 
towards this behaviour and how it relates to the distribution patterns observed in this species in the intertidal.

If we break it down, S. australis larvae may have responded first to the soluble conspecific cue in the water, which would have induced settlement behaviour in the adult-conditioned FSW treatments. As larvae actively swam downwards in response to this, they may have been searching for a conspecific cue adsorbed to the surface of a particular substrata. Larvae did not exhibit metamorphosis in the adult-conditioned water cues without live adults present, suggesting that, although the soluble conspecific cue was present, a preferential substrate conspecific cue was absent and metamorphosis was not established. Hadfield \& Paul (2001) question whether the same cue that induces settlement simultaneously induces metamorphosis also, or perhaps there are different cues involved; a question which can be applied here. In the live adult treatments, a soluble conspecific cue as well as a substrate cue was present (i.e. the adult shells), leading to metamorphosis. This is a curious result, yet has been similarly observed in a study by Gould (1919), where female adults of several species of slipper limpet of the genus Crepidula were shown to secrete a diffusible substance which attracted larvae to settle and metamorphose on their shells. Not only does this provide evidence that adult shells can be a necessary instigator for metamorphosis, it also suggests that female adults play a part in this selection. Gould (1919) discovered that sexually undifferentiated larvae of C. plana developed into functional males in greater numbers and more rapidly if female adults were present at competence, compared to larvae that were isolated or reared in association with males. Coe (1953) also demonstrated that sexless juveniles of the two closely related species $C$. nivea and $C$. williamsi were attracted to metamorphose only to adult females of their own species. Given that gastropods are generally hermaphroditic, this kind of settlement pattern could be advantageous in terms of reproductive success in species that exhibit non-gregarious settlement, and could be the reasoning behind why S. australis larvae only metamorphosed when live adults were present. In this study, the sexes of the Siphonaria adults were unknown but the results from Gould (1919) and Coe's (1953) studies could be an interesting factor to consider in future research.

In summary, the developmental timeline for Siphonaria australis, from egg mass to juvenile stage, can now be confirmed. In the selected controlled temperature of $17^{\circ} \mathrm{C}$, the embryonic period takes approximately 7-8 days until hatching, with larvae emerging at an average size of $150 \mu \mathrm{m}$. A detailed description of the larval development for gastropod veligers can be given by Collier (1997). Larvae generally become competent to metamorphose within 3.5 - 4 weeks from hatching at said temperature, with shells $\sim 350 \mu \mathrm{m}$ in length at this stage, and growth rates plateauing after competence has been reached. Competent larvae can be induced to metamorphose within 24-48 hours when 
exposed to a conspecific chemical cue. Thereby, the successful culture of this species, up to metamorphosis, takes approximately six weeks.

\subsection{Future Directions}

Although there is a great deal of information on many aspects of the reproductive biology of this genus (reviewed by Hodgson, 1999), the biology of Siphonariid larvae is still largely unknown. A number of workers have successfully hatched Siphonaria larvae under laboratory conditions (e.g. Creese, 1980; Chambers \& McQuaid, 1994; Fischer \& Phillips, 2014), and larval studies would therefore seem feasible, yet increased investigations on larval physiology, behaviour, longevity, and whether these larvae can delay metamorphosis, and for how long, would provide a greater understanding of Siphonariid population dynamics, as well as aspects of intertidal community structure. The biology of Siphonariidae definitely warrants more attention, especially as this taxonomic family includes both feeding and non-feeding larval development - it would be interesting to observe how the larval durations and culturing requirements differ between the two.

The timing of larval settlement is crucial for successful recruitment. If larvae fail to encounter a suitable substrate or settlement cue, they may enter a "delay period", where metamorphosis is postponed (Scheltema, 1961; Hadfield \& Paul, 2001). The corresponding delaying capability, as well as the ultimate fate of larvae in the absence of a suitable substratum, varies greatly among species. For example, larvae of the echinoderm, Lytechinus picta are able to delay metamorphosis for up to 60 days (Hinegardner, 1969); larvae of the polychaete Spirorbis borealis, can delay metamorphosis for 12 hours (Williams 1964); and larvae of the gastropod Crepidula fornicata can delay metamorphosis for $\sim 2$ weeks to 1 month (Pechenik, 1980). It has been postulated that the length of a larva's life could be related to the level of difficulty it may experience in locating an appropriate environment for the adult phase (Bayne, 1965; Crisp, 1974). For instance, species exhibiting general adult habitat requirements may produce larvae with only limited metamorphic delay capabilities compared to those species which are more patchily distributed with specialised adult niches, where larvae may be able to prolong metamorphic delay to a greater extent (Pechenik, 1980). Originally, whether larvae could delay their settlement until a suitable habitat was unknown in Siphonariids (Hodgson, 1999). In preliminary trials, S. australis larvae were shown to delay metamorphosis in non-conspecific cue treatments, with larvae living up to two weeks past attaining competence. Although feeding still occurred, growth rates had plateaued.

A larva's ability to differentiate different substrata, as well as prolong their planktonic existence until it encounters a suitable substratum, has considerable ecological significance as it influences both 
future juvenile survival and larval dispersal potential (Thorson, 1950; Crisp, 1974). Despite this, actual delaying capabilities are unknown for most species, including that of Siphonaria spp., and the factors controlling the potential duration of the delay period are poorly understood (Pechenik, 1980).

Abundant data has demonstrated that many marine invertebrate larvae achieve success in locating optimal habitats for settlement and metamorphic growth by responding to site-specific chemical cues associated with conspecific individuals, requisite prey, microbial films, or algal/other benthic substrata (Crisp, 1974; Pawlik, 1992; Hadfield, 1998; Hadfield \& Paul, 2001). Over time, research on larval settlement has become more invested on identifying the chemical composition of settlement cues, as well as the signal-transduction mechanisms by which external cues stimulate morphogenetic transformations in larvae (Hadfield, 1998). In relation to this study, it is unknown what the chemical composition of the adult conspecific cue is. Future work should look into (1) attempting to isolate and identify the natural compounds in this chemical substance so that it can be clarified what it is exactly that is stimulating the metamorphic responses in S. australis larvae, (2) researching the signaltransduction mechanisms by which external cues stimulate the morphogenetic transformation(s), and (3) identifying where the chemoreception that picks up on conspecific cues occurs. Marine invertebrates which require a chemical cue for settlement must have developed specialised chemosensory organs that are sensitive to responding to environmental inputs, resulting in the deposition of larvae in a location which guarantees a high probability of survival and successful reproduction (Rittschof et al., 1998). For Siphonariids, the location and sensory structure for chemoreception, that results in site-specific larval settlement, is unknown, however, there may be some insight towards which larval structure is responsible for picking up on conspecific chemical cues. Hadfield et al. (2000) discovered that the apical sensory organ (ASO) of gastropod veliger larvae is the potential site of perception of cues for settlement and metamorphosis, using the tropical nudibranch Phestilla sibogae as an example. According to Page (2002), "this exciting result is the first experimental evidence supporting previous speculation that the ASO of marine invertebrate larvae perceives metamorphic signalling cues". It makes for a good starting point into deciphering if the same applies to Siphonaria larvae.

In some marine invertebrate larvae, specific habitat cues are required to induce settlement and metamorphosis. However, as larvae age, these requirements may become less rigorous, with older larvae settling haphazardly on any available surface, or in response to a wider suite of cues; a process known as "decreasing selectivity" (Knight-Jones, 1953; Gibson, 1995). As time in the plankton lengthens, older larvae can be viewed as becoming increasingly "desperate" to settle, a conceptual model known as "the desperate larva hypothesis" (Toonen \& Pawlik, 2001; Marshall \& Keough, 
2003). This hypothesis elaborates that the longer a larva remains in the plankton, the more costs or risks it accumulates (Elkin \& Marshall, 2007). In this study, if more larvae had been available when settlement trials were being undertaken, it would have been interesting to test the idea of the "desperate larva hypothesis", and observe if larvae became less specific in their settlement cue requirements the longer they delayed metamorphosis.

In general, any attempt to explain the success of an organism in its habitat must consider all developmental stages of the individual, in order to understand how every stage links together towards the adaptation and survival of that organism. It is understandable that majority of studies have focused mainly on one life stage, or studied carry-over effects from the embryonic to early larval stage, as these can be considered "easy" to achieve and observe in a lab. It is surprising, however, that no dedicated attempts had been made to culture Siphonaria through to settlement in laboratory conditions, especially in terms of how many research opportunities this would create. Reasoning could be that it has just proven to be too difficult. The closest example is that of Zischke (1974), who was able to maintain the veligers of Siphonaria pectinata for 11 days in the laboratory, but the larvae did not feed nor settle. Ocaña \& Emson (1999) even mention that the duration of the planktonic phase of S. pectinata is unknown, after a non-vigorous attempt at achieving settlement themselves. Here, the successful culture of $S$. australis now enables work to be carried out into further life stages. Beforehand, studies involving S. australis had been limited to examination at only one life stage (Russell, 2008; Russell \& Phillips, 2009a;b), or the very early life stages (i.e. egg mass to larval stage) (Fischer, 2012; Fischer \& Phillips, 2014), restricting our knowledge of this species' biology and underestimating elements such as the cumulative effects of environmental stressors. Now that the door has been opened to investigate aspects beyond the larval stage, research can explore how environmental conditions influence vulnerability in the juvenile, and adult, stages, and how carryover effects of stress experienced at one life stage may manifest across these different transitions (i.e. parent to offspring, egg mass to planktonic larva, larva to juvenile). This will provide a greater understanding towards the importance of legacy effects, and also the influences it can have on the population dynamics and community structure of this species. Aside from carry-over effects, we will now also be able to attempt to culture individuals from juvenile through to maturation (i.e. reproductive adult), as this still remains unknown and is beneficial in completing the knowledge for the entire life history cycle of this species.

Other future work worth considering would be to observe how tropical Siphonariid species differ in their larval rearing requirements compared to temperate species, especially as tropical waters are vastly different in their phytoplanktonic concentrations, as well as algal species grow under a 
completely different regime in the tropics vs. temperate oceans. Larvae of Siphonaria from different habitats may respond to the feeding regime and settlement cues used in this study in a different manner.

Also, abundant literature attests that for many coastal marine species, larval settlement behaviour is influenced by the distribution of adults (Burke, 1986; Chase \& Bailey, 1996; Browne \& Zimmer, 2001; Werner \& Rothhaupt, 2007). Seeing as S. australis do not exhibit aggregative behaviour in the field, it would be interesting to observe how larvae respond to settlement cues under different adult densities. For example, a field experiment on the golden mussel Limnoperna fortunei, a gregarious species, was conducted to assess the influence of conspecific adult densities on larval recruitment success (Sardiña et al., 2009). Results indicated that recruitment was strongly affected by the presence and density of conspecifics, with larval recruitment being significantly higher in treatments with higher adult densities, as well as growth rates of newly-settled juveniles were also significantly higher. Although such results would be expected in a gregarious species, it would be interesting to observe if adult densities affect larval settlement in a non-gregarious species, and obtain further understanding towards the structure and distribution of adult populations in the field.

In summary, there is much work that needs to be done in regards to further understanding the biology of Siphonariid limpets. A major gap in the knowledge of the life history of Siphonaria australis has now been filled and, with this culturing method, we can now work towards obtaining a greater understanding of the development and ecological processes behind the larval settlement and metamorphosis of the Siphonaria genus. Although they are not considered economically important, it is always imperative to understand as much of the ecology of a species as is possible, especially if significant ecological interactions relating to community structures are involved. A better understanding of the life history of $S$. australis can also lead to the development of population models regarding this species, which could aid in predicting the spatial patterns of larval recruitment. Understanding the processes that lead to the colonisation of substrata by any larval invertebrate is crucial in determining the ecology of marine communities. In conclusion, this culture method will help in linking the life history of this species into broader contexts of developmental biology, ecology, and aquaculture. All in all, the successful culture of Siphonaria australis offers a wide range of research opportunities in the field of marine science. 


\section{References}

- Allison G.W (1994) Effects of the temporary starvation on larvae of the sea star Asterina miniata. Marine Biology, 188: 255-261

- Aranda-Burgos J.A, da Costa F., Nóvoa S., Ojea J., Martínez-Patiño D. (2014) Effects of microalgal diet on growth, survival, biochemical and fatty acid composition of Ruditapes decussatus larvae. Aquaculture, 420: 38-48

- Ayal Y., Safriel U.N (1982) r-Curves and the cost of the planktonic stage. American Naturalist,:391-401

- Barlow L.A (1990) Electrophysiological and behavioral responses of larvae of the red abalone (Haliotis rufescens) to settlement-inducing substances. Bulletin of Marine Science, 46: 537-554

- Barnes J., Gonor J. (1973) The larval settling response of the lined chiton Tonicella lineata. Marine Biology, 20: 259-264

- Basch L., Pearse J. (1996) Consequences of larval feeding environment for settlement and metamorphosis of a temperate echinoderm. Oceanologica acta, 19: 273-285

- Bayne B.L (1969) The gregarious behaviour of the larvae of Ostrea edulis L. at settlement. Journal of the Marine Biological Association of the United Kingdom, 49: 327-356

- Bayne B.L (1965) Growth and delay of metamorphosis of the larvae of Mytilus edulis (L.). Ophelia, 2(1): 1-47

- Becker W. (2004) Microalgae for aquaculture. The nutritional value of microalgae for aquaculture. In: Richmond A. (ed): Handbook of Microalgal Culture, Blackwell, Oxford.

- Bell J.L (1993) Feeding and growth of prosobranch veligers. (Doctoral dissertation). University of Hawaii, Hawaii.

- Black R. (1979) Competition between intertidal limpets: an intrusive niche on a steep resource gradient. The Journal of Animal Ecology,: 401-411

- Bonar D.B, Hadfield M.G (1974) Metamorphosis of the marine gastropod Phestilla sibogae Bergh (Nudibranchia: Aeolidacea). I. Light and electron microscopic analysis of larval and metamorphic stages. Journal of Experimental Marine Biology and Ecology, 16: 227-255

- Bos O.G, Hendriks I.E, Strasser M., Dolmer P., Kamermans P. (2006) Estimation of food limitation of bivalve larvae in coastal waters of north-western Europe. Journal of Sea Research, 55: 191-206 
- Bowen S.H (1987) Composition and nutritional value of detritus. In: Moriarty D.J.W., Pullin R.S.V. (eds): Detritus and Microbial Ecology in Aquaculture: Proceedings of the Conference on Detrital Systems for Aquaculture. ICLARM Conference Proceedings, 14: 192-216

- Brancato M., Woollacott R. (1982) Effect of microbial films on settlement of bryozoan larvae (Bugula simplex, B. stolonifera and B. turrita). Marine Biology, 71: 51-56

- Branch G. (1985) Limpets: evolution and adaptation. In: The Mollusca, (10): 187-220. Academic Press, Orlando.

- Branch G.M (1981) The biology of limpets: physical factors, energy flow, and ecological interactions. Oceanography and Marine Biology: an Annual Review, 19: 235-380

- Branch G.M (1986) Limpets: their role in littoral and sublittoral community dynamics. In: Moore P.G, Seed R. (eds): The Ecology of Rocky Coasts. Columbia University Press, New York.

- Brown M.R (2002) Nutritional value and use of microalgae in aquaculture. Avances en Nutrición Acuícola VI Memorias del VI Simposium Internacional de Nutrición Acuícola, 3: 281-292

- Brown M.R, Garland C.D, Jeffrey S.W, Jameson I.D, Leroi J.M (1993) The gross and amino acid compositions of batch and semi-continuous cultures of Isochrysis sp. (clone T. ISO), Pavlova lutheri and Nannochloropsis oculata. Journal of Applied Phycology, 5: 285-296

- Brown M.R, Jeffrey S.W, Volkman J.K, Dunstan G.A (1997) Nutritional properties of microalgae for mariculture. Aquaculture, 151: 315-331

- Browne K.A, Zimmer R.K (2001) Controlled field release of a waterborne chemical signal stimulates planktonic larvae to settle. The Biological Bulletin, 200: 87-91

- Burke R.D (1983) The induction of metamorphosis of marine invertebrate larvae: stimulus and response. Canadian Journal of Zoology, 61: 1701-1719

- Burke RD (1986) Pheromones and the gregarious settlement of marine invertebrate larvae. Bulletin of Marine Science, 39: 323-331

- Cameron R.A, Hinegardner R.T (1974) Initiation of metamorphosis in laboratory cultured sea urchins. The Biological Bulletin, 146: 335-342

- Canuel E.A, Martens C.S (1993) Seasonal variations in the sources and alteration of organic matter associated with recently-deposited sediments. Organic Geochemistry, 20: 563-577

- Capo T.R, Bardales A.T, Gillette P.R, Lara M.R, Schmale M.C, Serafy J.E (2009) Larval growth, development, and survival of laboratory-reared Aplysia californica: Effects of diet and veliger density. Comparative Biochemistry and Physiology Part C: Toxicology \& Pharmacology, 149: 215-223 
- Carleton J., Sammarco P.W (1987) Effects of substratum irregularity on success of coral settlement: quantification by comparative geomorphological techniques. Bulletin of Marine Science, 40: 85-98

- Chambers R., McQuaid C. (1994) A review of larval development in the intertidal limpet genus Siphonaria (Gastropoda: Pulmonata). Journal of Molluscan Studies, 60: 415-423

- Chase M.E, Bailey R.C (1996) Recruitment of Dreissena polymorpha: does the presence and density of conspecifics determine the recruitment density and pattern in a population? Malacologia, 38: 19-31

- Chia F., Koss R. (1978) Development and metamorphosis of the planktotrophic larvae of Rostanga pulchra (Mollusca: Nudibranchia). Marine Biology 46: 109-119

- Chia F-S., Koss R. (1988) Induction of settlement and metamorphosis of the veliger larvae of the nudibranch, Onchidoris bilamellata. International Journal of Invertebrate Reproduction and Development, 14: 53-69

- Chino Y., Saito M., Yamasu K., Suyemitsu T., Ishihara K. (1994) Formation of the adult rudiment of sea urchins is influenced by thyroid hormones. Developmental Biology 161: 1-11

- Chiu J.M.Y, Ng T.Y.T, Wang W.X, Thiyagarajan V., Qian P-Y. (2007) Latent effects of larval food limitation on filtration rate, carbon assimilation and growth in juvenile gastropod Crepidula onyx. Marine Ecology Progress Series, 343: 173-182

- Coe W.R (1953) Influences of association, isolation, and nutrition on the sexuality of snails of the genus Crepidula. Journal of Experimental Zoology, 122: 5-19

- Collier J.R (1997) Gastropods, The Snails. In: Gilbert SF, Raunio AM (eds): Embryology: Constructing The Organism. Sinauer Associates, Inc, U.S.A.

- Coon S.L, Fitt W.K, Bonar D.B (1990) Competence and delay of metamorphosis in the Pacific oyster Crassostrea gigas. Marine Biology, 106: 379-387

- Corkett C. (1972) Development rate of copepod eggs of the genus Calanus. Journal of Experimental Marine Biology and Ecology, 10: 171-175

- Creese R., Underwood A. (1982) Analysis of inter-and intra-specific competition amongst intertidal limpets with different methods of feeding. Oecologia, 53: 337-346

- Creese R.G (1980) Reproductive cycles and fecundities of two species of Siphonaria (Mollusca: Pulmonata) in south-eastern Australia. Australian Journal of Marine Freshwater Research, 31: $37-47$ 
- Crisp D. (1961) Territorial behaviour in barnacle settlement. Journal of Experimental Biology 38 : 429-446

- Crisp D., Barnes H. (1954) The orientation and distribution of barnacles at settlement with particular reference to surface contour. The Journal of Animal Ecology,: 142-162

- Crisp D.J (1974) Factors influencing the settlement of marine invertebrate larvae. In: Grant P.T, Mackie A.M (eds): Chemoreception in Marine Organisms. Academic Press, New York.

- Crisp D.J (1988) Reduced discrimination of laboratory-reared cyprids of the barnacle Balanus amphitrite amphitrite Darwin, Crustacea Cirripedea, with a description of a common abnormality. In: Thompson M.F, Sarojini R., Nagabushanam R. (eds):, Marine Biodeterioration, I.B.H. Publ. Co., New Delhi.

- Cruz-Rivera E., Hay M.E (2000) Can quantity replace quality? Food choice, compensatory feeding, and fitness of marine mesograzers. Ecology, 81: 201-219

- Davis H.C, Guillard R.R (1958) Relative value of ten genera of micro-organisms as foods for oyster and clam larvae. US Government Printing Office.

- Delaunay F., Marty Y., Moal J., Samain J-F. (1993) The effect of monospecific algal diets on growth and fatty acid composition of Pecten maximus (L.) larvae. Journal of Experimental Marine Biology and Ecology, 173: 163-179

- Doyle R. (1975) Settlement of planktonic larvae: a theory of habitat selection in varying environments. American Naturalist, 109: 113-126

- Eckert G.L (1995) A novel larval feeding strategy of the tropical sand dollar Encope michelinii (Agassiz): Adaptation to food limitation and an evolutionary link between planktotrophy and lecithotrophy. Journal of Experimental Marine Biology and Ecology, 187: 103-128

- Elkin C., Marshall D.J (2007) Desperate larvae: influence of deferred costs and habitat requirements on habitat selection. Marine Ecology Progress Series, 335: 143-153

- Eyster L.S, Pechenik J.A (1988) Attachment of Mytilus edulis L. larvae on algal and byssal filaments is enhanced by water agitation. Journal of Experimental Marine Biology and Ecology,114: 99-110

- FAO (2012) The State of World Fisheries and Aquaculture. In: Food and Agriculture Organisation of the United Nations, Rome.

- Fenaux L., Srathmann M.F, Strathmann R.R (1994) Five tests of food-limited growth of larvae in coastal waters by comparisons of rates of development and form of echinoplutei. Limnology and Oceanography, 39: 84-98 
- Fischer J. (2012) Effects of environmental stressors on the early development of intertidal and subtidal gastropod embryos. Master of Science Thesis, Victoria University of Wellington, New Zealand.

- Fischer J., Phillips N.E (2014) Carry-over effects of multiple stressors on benthic embryos are mediated by larval exposure to elevated UVB and temperature. Glob. Chang. Biol., 20: 2108-2116

- Fretter V., Montgomery M.C (1968) The treatment of food by prosobranch veligers. Journal of the Marine Biological Association of the United Kingdom 48: 499-520

- Gebauer P., Walter I., Anger K. (1998) Effects of substratum and conspecific adults on the metamorphosis of Chasmagnathus granulata (Dana) (Decapoda: Grapsidae) megalopae. Journal of Experimental Marine Biology and Ecology, 223: 185-198

- Gibson G. (1995) Why be choosy? Temporal changes in larval sensitivity to several naturallyoccurring metamorphic inducers in the opisthobranch Haminaea callidegenita. Journal of Experimental Marine Biology and Ecology, 194: 9-24

- Glass G.V, Peckham P.D, Sanders J.R (1972) Consequences of failure to meet assumptions underlying the fixed effects analyses of variance and covariance. Review of Educational Research, 42: $237-288$

- Gould H.N (1919) Studies on sex in the hermaphrodite mollusc Crepidula plana. III. Transference of the male-producing stimulus through sea-water. Journal of Experimental Zoology, 29: 113-120

- Grice G.D (1971) The developmental stages of Eurytemora americana Williams, 1906, and Eurytemora herdmani Thompson \& Scott, 1897 (Copepoda, Calanoida). Crustaceana, 20: 145158

- Gruffydd L.D, Beaumont A.R (1972) A method for rearing Pecten maximus larvae in the laboratory. Marine Biology, 15: 350-355

- Guedes A.C, Malcata F.X (2012) Nutritional value and uses of microalgae in aquaculture. INTECH Open Access Publisher.

- Hadfield M., Paul V.J (2001) Natural chemical cues for settlement and metamorphosis of marineinvertebrate larvae. Marine Chemical Ecology,: 431-461

- Hadfield M.G (1978) Metamorphosis in marine molluscan larvae: an analysis of stimulus and response. Settlement and Metamorphosis of Marine Invertebrate Larvae,: 165-175

- Hadfield M.G (1986) Settlement and recruitment of marine invertebrates: a perspective and some proposals. Bulletin of Marine Science, 39: 418-425 
- Hadfield M.G (1998) The DP Wilson lecture: Research on settlement and metamorphosis of marine invertebrate larvae: past, present and future. Biofouling, 12: 9-29

- Hadfield M.G, Meleshkevitch E.A, Boudko D.Y (2000) The apical sensory organ of a gastropod veliger is a receptor for settlement cues. The Biological Bulletin, 198: 67-76

- Hansson S., Rudstam L.G, Johansson S. (1990) Are marine planktonic invertebrates food limited? The case of Mysis mixta (Crustacea, Mysidacea) in the Baltic Sea. Oecologia, 84: 430-432

- Harrison P.J, Thompson P.A, Calderwood G.S (1990) Effects of nutrient and light limitation on the biochemical composition of phytoplankton. Journal of Applied Phycology, 2:45-56

- Hawkins S.J, Hartnoll R. (1983) Grazing of intertidal algae by marine invertebrates. Oceanography and Marine Biology, 21: 195-282

- Hay M.E (2009) Marine Chemical Ecology: Chemical Signals and Cues Structure Marine Populations, Communities, and Ecosystems. Annual Review of Marine Science, 1: 193-212

- Helm M.M (1977) Mixed algal feeding of Ostrea edulis larvae with Isochrysis galbana and Tetraselmis suecica. Journal of the Marine Biological Association of the United Kingdom, 57: 1019-1029

- Hidu H., Valleau W.G, Veitch F.P (1979) Gregarious setting in european and american oysters: response to surface chemistry vs. waterborne pheromones. Proc. Natl. Shellfish. Assoc., 68 (11)

- Highsmith R.C (1982) Induced settlement and metamorphosis of sand dollar (Dendraster ecentricus) larvae in predator-free sites: adult sand dollar beds. Ecology,: 329-337

- Highsmith R.C, Emlet R.B (1986) Delayed metamorphosis: effect on growth and survival of juvenile sand dollars (Echinoidea: Clypeasteroida). Bulletin of Marine Science, 39: 347-361

- Hinchcliffe P., Riley J. (1972) The effect of diet on the component fatty-acid composition of Artemia salina. Journal of the Marine Biological Association of the United Kingdom, 52: 203-211

- Hinegardner R.T (1969) Growth and development of the laboratory cultured sea urchin. The Biological Bulletin, 137: 465-475

- His E., Seaman M.N.L (1992) Effects of temporary starvation on the survival, and subsequent feeding and growth, of oyster (Crassostrea gigas) larvae. Marine Biology, 114: 277-279

- Hodgson A.N (1999) The biology of siphonariid limpets (Gastropoda: Pulmonata). Oceanography and Marine Biology: an Annual Review, 37: 245-314

- Hoegh-Guldberg O., Pearse J.S (1995) Temperature, food availability, and the development of marine invertebrate larvae. American Zoologist, 35: 415-425 
- Hurst A. (1967) The egg masses and veligers of thirty northeast Pacific opisthobranchs. Veliger, 9: $255-288$

- Iwasaki H., Kamiya S. (1977) Cultivation of marine copepod Pseudodiaptomus marinus Sato. Bulletin of The Plankton Society of Japan, 24: 44-54

- Jackson G.A, Strathmann R.R (1981) Larval mortality from offshore mixing as a link between precompetent and competent periods of development. American Naturalist,: 16-26

- Jensen G.C (1989) Gregarious settlement by megalopae of the porcelain crabs Petrolisthes cinctipes (Randall) and P. eriomerus Stimpson. Journal of Experimental Marine Biology and Ecology, 131: 223-231

- Jensen R.A, Morse D.E (1984) Intraspecific facilitation of larval recruitment: gregarious settlement of the polychaete Phragmatopoma californica (Fewkes). Journal of Experimental Marine Biology and Ecology, 83: 107-126

- Jensen R.A, Morse D.E (1990) Chemically induced metamorphosis of polychaete larvae in both the laboratory and ocean environment. Journal of Chemical Ecology, 16: 911-930

- Johnson C.R, Lewis T.E, Nichols D.S, Degnan B.M (1997) Bacterial induction of settlement and metamorphosis in marine invertebrates. In: Proceedings of the 8th International Coral Reef Symposium, 2: 1219-1224. Smithsonian Tropical Research Institute.

- Kempf S.C (1981) Long-lived larvae of the gastropod Aplysia juliana: do they disperse and metamorphose or just slowly fade away? Mar. Ecol.Prog. Ser., 6: 65

- Kirchman D., Graham S., Reish D., Mitchell R. (1981) Bacteria induce settlement and metamorphosis of Janua (Dexiospira) brasiliensis Grube (Polychaeta: Spirprbidae). Journal of Experimental Marine Biology and Ecology, 56: 153-163

- Klinzing M.S.E, Pechenik J.A (2000) Evaluating whether velar lobe size indicates food limitation among larvae of the marine gastropod Crepidula fornicata. Journal of Experimental Marine Biology and Ecology, 252: 255-279

- Knight-Jones E.W (1953) Decreased discrimination during setting after prolonged planktonic life in larvae of Spirorbis borealis (Serpulidae). Journal of the Marine Biological Association of the United Kingdom, 32: 337-345

- Kon T. (1979) Ecological studies on larvae of the crabs belonging to the genus Chionoecetes. 1. The influence of starvation on the survival and growth of the Zuwai crab. Bulletin of the Japanese Society of Scientific Fisheries, 45: 7-9 
- Kreeger D., Goulden C., Kilham S., Lynn S., Datta S., Interlandi S. (1997) Seasonal changes in the biochemistry of Lake Seston. Freshwater Biology, 38: 539-554

- Lavens P., Sorgeloos P. (1996) Manual on the Production and Use of Live Food for Aquaculture. Food and Agriculture Organization (FAO).

- Levings S.C, Garrity S.D (1986) Notes on reproduction of a tropical pulmonate limpet, Siphonaria gigas (Sowerby). The Veliger, 29: 86-90

- Little C. (1989) Factors governing patterns of foraging activity in littoral marine herbivorous molluscs. Journal of Molluscan Studies, 55: 273-284

- Loosanoff V.L, Davis H.C (1963) Rearing of bivalve mollusks. Advances in Marine Biology, 1: 1136

- Lubchenco J., Gaines S.D (1981) A unified approach to marine plant-herbivore interactions. I. Populations and communities. Annual Review of Ecology and Systematics, 12: 405-437

- Lucas J. (1983) Quantitative studies of feeding and nutrition during larval development of the coral reef asteroid Acanthaster planci (L.). Journal of Experimental Marine Biology and Ecology, 65: 173-193

- Marshall D.J, Keough M.J (2003) Variation in the dispersal potential of non-feeding invertebrate larvae: the desperate larva hypothesis and larval size. Marine Ecology Progress Series, 255: 145153

- McEdward L.D (1995) Ecology of Marine Invertebrate Larvae. CRC Press, Boca Raton, FL.

- McEdward L.R, Qian P-Y. (2001) Effects of the duration and timing of starvation during larval life on the metamorphosis and initial juvenile size of the polychaete Hydroides elegans (Haswell). Journal of Experimental Marine Biology and Ecology, 261: 185-197

- Meadows P.S, Campbell J.I (1972) Habitat selection by aquatic invertebrates. In: Russell F.S, Yongee M. (eds): Advances in Marine Biology, Book 10. Academic Press, New York.

- Mileikovsky S.A (1971) Types of larval development in marine bottom invertebrates, their distribution and ecological significance: a re-evaluation. Marine Biology, 10: 193-213

- Miller B.A, Emlet R.B (1999) Development of newly metamorphosed juvenile sea urchins (Strongylocentrotus franciscanus and S. purpuratus): morphology, the effects of temperature and larval food ration, and a method for determining age. Journal of Experimental Marine Biology and Ecology, 235: 67-90 
- Morse A.N, Morse D.E (1984) Recruitment and metamorphosis of Haliotis larvae induced by molecules uniquely available at the surfaces of crustose red algae. Journal of Experimental Marine Biology and Ecology, 75: 191-215

- Morse D.E (1990) Recent progress in larval settlement and metamorphosis: closing the gaps between molecular biology and ecology. Bulletin of Marine Science, 46: 465-483

- Morse D.E, Hooker N., Duncan H., Jensen L. (1979) $\gamma$-Aminobutyric acid, a neurotransmitter, induces planktonic abalone larvae to settle and begin metamorphosis. Science, 204: 407-410

- Morse D.E, Tegner M., Duncan H., Hooker N., Trevelyan G., Cameron A. (1980) Induction of settling and metamorphosis of planktonic molluscan (Haliotis) larvae. III: Signaling by metabolites of intact algae is dependent on contact. In: Chemical Signals. Springer US, : 67-86

- Moyse J. (1963) A comparison of the value of various flagellates and diatoms as food for barnacle larvae. Journal du Conseil, 28: 175-187

- Newkirk G.F, Waugh D.L (1980) Inhibitory effect of the alga Pavlova lutheri on growth of mussel, Mytilus edulis, larvae. Fishery Bulletin, 77: 715-718

- Nichols D.S (2003) Prokaryotes and the input of polyunsaturated fatty acids to the marine food web. FEMS Microbiology Letters, 219:1-7

- Noble W.J, Benkendorff K., Harris J.O (2015) Growth, settlement and survival of Dicathais orbita (Neogastropoda: Mollusca) larvae in response to temperature, diet and settlement cues. Aquaculture Research, 46:1455-1468

- O'Connor N.J (1991) Flexibility in timing of the metamorphic molt by fiddler crab megalopae Uca pugilator. Marine Ecology Progress Series, 68: 243-247

- O'Connor W.A, Heasman M.P (1997) Diet and feeding regimens for larval doughboy scallops, Mimachlamys asperrima. Aquaculture, 158: 289-303

- Ocaña T.M, Emson R.H (1999) Maturation, spawning and development in Siphonaria pectinata Linnaeus (Gastropoda: Pulmonata) at Gibraltar. Journal of Molluscan Studies, 65: 185-193

- Olson R.R, Olson M.H (1989) Food limitation of planktotrophic marine invertebrate larvae: does it control recruitment success? Annual Review of Ecology and Systematics,: 225-247

- Ortega S. (1985) Competitive interactions among tropical intertidal limpets. Journal of Experimental Marine Biology and Ecology 90: 11-25

- Padilla D.K, McCann M.J, Glenn M.M, Hooks A.P, Shumway S.E (2014) Effect of food on metamorphic competence in the model system Crepidula fornicata. The Biological Bulletin 227: 242-251 
- Page L.R (2002) Comparative structure of the larval apical sensory organ in gastropods and hypotheses about function and developmental evolution. Invertebrate Reproduction \& Development, 41: 193-200

- Parsons G., Dadswell M., Roff J. (1993) Influence of biofilm on settlement of sea scallop, Placopecten magellanicus (Gmelin, 1791), in Passamaquoddy Bay, New Brunswick, Canada. Journal of Shellfish Research, 12: 279-283

- Paul A.J, Paul J.M (1980) The effect of early starvation on later feeding success of king crab zoeae. Journal of Experimental Marine Biology and Ecology, 44: 247-251

- Paulay G., Boring L., Strathmann R.R (1985) Food limited growth and development of larvae: Experiments with natural sea water. Journal of Experimental Marine Biology and Ecology, 93:110

- Pawlik J.R (1986) Chemical induction of larval settlement and metamorphosis in the reef-building tube worm Phragmatopoma californica (Sabellariidae: Polychaeta). Marine Biology, 91: 59-68

- Pawlik J.R (1992) Chemical ecology of the settlement of benthic marine invertebrates. Oceanogr. Mar. Biol. Annu. Rev., 30: 273-335

- Pawlik JR, Faulkner JD (1986) Specific free fatty acids induce larval settlement and metamorphosis of the reef-building tube worm Phragmatopoma califomica (Fewkes). Journal of Experimental Marine Biology and Ecology, 102: 301-310

- Pawlik J.R, Hadfield M.G (1990) A symposium on chemical factors that influence the settlement and metamorphosis of marine invertebrate larvae: introduction and perspective. Bulletin of Marine Science, 46: 450-454

- Payne M.F, Rippingale R.J (2000) Evaluation of diets for culture of the calanoid copepod Gladioferens imparipes. Aquaculture, 187: 85-96

- Pearce C.M, Scheibling R.E (1990) Induction of metamorphosis of larvae of the green sea urchin, Strongylocentrotus droebachiensis, by coralline red algae. The Biological Bulletin, 179: 304-311

- Pearce J.S, Arch S.W (1969) The aggregation behavior of Diadema (Echinodermata: Echinoidea). Micronesica, 51: 166-171

- Pechenik J.A (1979) Role of encapsulation in invertebrate life histories. American Naturalist,: 859870

- Pechenik J.A (1980) Growth and energy balance during the larval lives of three prosobranch gastropods. Journal of Experimental Marine Biology and Ecology, 44: 1-28 
- Pechenik J.A (1984) The relationship between temperature, growth rate, and duration of planktonic life for larvae of the gastropod Crepidula fornicata (L.). Journal of Experimental Marine Biology and Ecology, 74: 241-257

- Pechenik J.A (1987) Environmental influences of larval survival and development. In: Giese A.C, Pearse J.S, Pearse V.B (eds): Reproduction of Marine Invertebrates, Book 9. Blackwell, California.

- Pechenik J.A (1990) Delayed metamorphosis by larvae of marine benthic invertebrates: Does it occur? Is there a price to pay? Ophelia, 32: 63-94

- Pechenik J.A, Estrella M.S, Hammer K. (1996a) Food limitation stimulates metamorphosis of competent larvae and alters postmetamorphic growth rate in the marine prosobranch gastropod Crepidula fornicata. Marine Biology 127: 267-275

- Pechenik J.A, Eyster L.S (1989) Influence of delayed metamorphosis on the growth and metabolism of young Crepidula fornicata (Gastropoda) juveniles. The Biological Bulletin, 176: 14-24

- Pechenik J.A, Eyster L.S, Widdows J., Bayne B.L (1990) The influence of food concentration and temperature on growth and morphological differentiation of blue mussel Mytilus edulis L. larvae. Journal of Experimental Marine Biology and Ecology, 136: 47-64

- Pechenik J.A, Fisher N.S (1979) Feeding, assimilation, and growth of mud snail larvae, Nassarius obsoleyus (Say), on three different algal diets. Journal of Experimental Marine Biology and Ecology, 38: 57-80

- Pechenik J.A, Gee C.C (1993) Onset of metamorphic competence in larvae of the gastropod Crepidula fornicata (L.), judged by a natural and artifical cue. Journal of Experimental Marine Biology and Ecology, 167: 59-72

- Pechenik J.A, Hammer K., Weise C. (1996b) The effect of starvation on acquisition of competence and post-metamorphic performance in the marine prosobranch gastropod Crepidula fornicata (L.). Journal of Experimental Marine Biology and Ecology, 199: 137-152

- Pechenik J.A, Heyman W.D (1987) Using KCl to determine size at competence for larvae of the marine gastropod Crepidula fornicata (L.). Journal of Experimental Marine Biology and Ecology, 112: $27-38$

- Pechenik J.A, Lima G.M (1984) Relationship between growth, differentiation, and length of larval life for individually reared larvae of the marine gastropod, Crepidula fornicata. The Biological Bulletin, 166: 537-549 
- Pechenik J.A, Marsden I.D, Pechenik O. (2003) Effects of temperature, salinity, and air exposure on development of the estuarine pulmonate gastropod Amphibola crenata. Journal of Experimental Marine Biology and Ecology, 292: 159-176

- Pechenik J.A, Rittschof D., Schmidt A.R (1993) Influence of delayed metamorphosis on survival and growth of juvenile barnacles Balanus amphitrite. Marine Biology, 115: 287-294

- Perron F.E (1980) Laboratory culture of the larvae of Conus textile Linne (Gastropoda: Toxoglossa). Journal of Experimental Marine Biology and Ecology, 42: 27-38

- Persoone G., Claus C. (1980) Mass culture of algae: a bottleneck in the nursery culturing of molluscs. Algae Biomass. North-Holland Biomedical Press, Amsterdam.

- Perumal S., Thirunavukkarasu A.R, Pachiappan P. (2015) Advances in Marine and Brackishwater Aquaculture. Springer, India.

- Phillips N.E (2002) Effects of nutrition-mediated larval condition on juvenile performance in a marine mussel. Ecology, 83: 2562-2574

- Phillips N.E (2004) Variable timing of larval food has consequences for early juvenile performance in a marine mussel. Ecology, 85: 2341-2346

- Phillips N.E, Shima J.S (2006) Differential effects of suspended sediments on larval survival and settlement of New Zealand urchins Evechinus chloroticus and abalone Haliotis iris. Marine Ecology Progress Series, 314: 149-158

- Pilkington M.C, Fretter V. (1970) Some factors affecting the growth of prosobranch veligers. Helgoländer wissenschaftliche Meeresuntersuchungen, 20: 576-593

- Pillsbury K.S (1985) The relative food value and biochemical composition of five phytoplankton diets for queen conch, Strombus gigas (Linne) larvae. Journal of Experimental Marine Biology and Ecology, 90: 221-231

- Plaut I., Borut A., Spira M.E (1995) Growth and metamorphosis of Aplysia oculifera larvae in laboratory culture. Marine Biology, 122: 425-430

- Przeslawski R., Perino L., Padilla D.K (2012) Effects of larval density and food rations on the larval development of an ecologically important bivalve (Mercenaria mercenaria). Molluscan Research, 32(1): 27-35

- Puello-Cruz A.C, Mezo-Villalobos S., González-Rodríguez B., Voltolina D. (2009) Culture of the calanoid copepod Pseudodiaptomus euryhalimus (Johnson 1939) with different algal diets. Aquaculture, 290: 317-319 
- Qian P-Y., Chia F-S. (1991) Fecundity and egg size are mediated by food quality in the polychaete worm Capitellasp. Journal of Experimental Marine Biology and Ecology, 148: 11-25

- Qian P-Y., Chia F-S. (1993) Larval development as influenced by food limitation in two polychaetes: Capitella sp. and Polydora ligni Webster. Journal of Experimental Marine Biology and Ecology, 166: 93-105

- Qian P-Y., McEdward L.R, Chia F-S. (1990) Effects of delayed settlement on survival, growth, and reproduction in the spionid polychaete, Polydora ligni. Invertebrate Reproduction and Development, 18: 147-152

- Qian P-Y., Pechenik J.A (1998) Effects of larval starvation and delayed metamorphosis on juvenile survival and growth of the tube-dwelling polychaete Hydroides elegans (Haswell). Journal of Experimental Marine Biology and Ecology, 227: 169-185

- Raimondi P.T (1988) Settlement cues and determination of the vertical limit of an intertidal barnacle. Ecology, : 400-407

- Raimondi P.T (1990) Patterns, mechanisms, consequences of variability in settlement and recruitment of an intertidal barnacle. Ecological Monographs, : 283-309

- Raymont J.E.G (1980) Plankton and Productivity in the Oceans. Volume 1. Pergamon Press, New York.

- Renaud S.M, Thinh L-V., Parry D.L (1999) The gross chemical composition and fatty acid composition of 18 species of tropical Australian microalgae for possible use in mariculture. Aquaculture, 170: 147-159

- Ritson-Williams R., Shjegstad S.M, Paul V.J (2009) Larval metamorphosis of Phestilla spp. in response to waterborne cues from corals. Journal of Experimental Marine Biology and Ecology, 375: $84-88$

- Rittschof D. (1985) Oyster drills and the frontiers of chemical ecology: Unsettling ideas. Am. Malacol.Bull.Spec. Ed., 1: 111-116

- Rittschof D., Branscomb E.S, Costlow J.D (1984) Settlement and behavior in relation to flow and surface in larval barnacles, Balanus amphitrite, Darwin. Journal of Experimental Marine Biology and Ecology, 82: 131-146

- Rittschof D., Forward Jr R., Cannon G., Welch J., McClary Jr M., Holm E., Clare A., Conova S., McKelvey L., Bryan P. (1998) Cues and context: larval responses to physical and chemical cues. Biofouling, 12: 31-44 
- Rodriguez S.R, Ojeda F.P, Inestrosa N.C (1993) Settlement of benthic marine invertebrates. Marine Ecology Progress Series Oldendorf, 97(2): 193-207

- Roughgarden J.G, Possingham H. (1988) Recruitment dynamics in complex life cycles. Science, 241: $1460-1466$

- Rowley R. (1989) Settlement and recruitment of sea urchins (Strongylocentrotus spp.) in a seaurchin barren ground and a kelp bed: are populations regulated by settlement or post-settlement processes? Marine Biology, 100: 485-494

- Russell J., Phillips N.E (2009a) Species-specific vulnerability of benthic marine embryos of congeneric snails (Haminoea spp.) to ultraviolet radiation and other intertidal stressors. The Biological Bulletin, 217: 65-72

- Russell J., Phillips N.E (2009b) Synergistic effects of ultraviolet radiation and conditions at low tide on egg masses of limpets (Benhamina obliquata and Siphonaria australis) in New Zealand. Marine Biology, 156: 579-587

- Russell J.M (2008) Effects of ultraviolet radiation (UVR) and other environmental stressors on the development of intertidal mollusc embryos. Master of Science Thesis, Victoria University of Wellington, Wellington, New Zealand.

- Sardiña P., Cataldo D.H, Boltovskoy D. (2009) Effects of conspecifics on settling juveniles of the invasive golden mussel, Limnoperna fortunei. Aquatic Sciences, 71: 479-486

- Satuito C.G, Shimizu K., Fusetani N. (1997) Studies on the factors influencing larval settlement in Balanus amphitrite and Mytilus galloprovincialis. Live Food in Aquaculture,: 275-280

- Scheltema R.S (1961) Metamorphosis of the veliger larvae of Nassarius obsoletus (Gastropoda) in response to bottom sediment. The Biological Bulletin, 120: 92-109

- Scheltema R.S (1967) The relationship of temperature to the larval development of Nassarius obsoletus (Gastropoda). The Biological Bulletin, 132: 253-265

- Scheltema R.S (1974) Biological interactions determining larval settlement of marine invertebrates. Thalassia jugoslavica, 10: 263-296

- Scheltema R.S (1986) On dispersal and planktotrophic larvae of benthic invertebrates: An eclectic overview and summary of the problems. Bulletin of Marine Science, 39: 290-322

- Sebens K.P (1983) Settlement and metamorphosis of a temperate soft-coral larva (Alcyonium siderium Verrill): induction by crustose algae. The Biological Bulletin, 165: 286-304 
- Seki T., Kan-No H. (1981) Induced settlement of the japanese abalone, Haliotis discus hannai, veliger by the mucous trails of the juvenile and adult abalones. Bulletin of Tohoku Regional Fisheries Research Laboratory, 43: 29-36

- Shepherd S., Turner J. (1985) Studies on southern australian abalone (genus Haliotis). VI. Habitat preference, abundance and predators of juveniles. Journal of Experimental Marine Biology and Ecology, 93: 285-298

- Shiraishi K., Provasoli L. (1959) Growth factors as supplements to inadequate algal foods for Tigriopus japonicus. Tohoku Journal of Agricultural Research, 10: 89-96

- Slattery M. (1992) Larval settlement and juvenile survival in the red abalone (Haliotis rufescens), an examination of inductive cues and substrate selection. Aquaculture, 102:143-153

- Slattery M. (1997) Chemical cues in marine invertebrate larval settlement. In: Nagabushanam R., Thompson M.F (eds): Fouling Organisms of the Indian Ocean: Biology and Control Technology,: 135-157. Oxford and IBH Publishing, New Delhi.

- Stoner A.W, Ray M., Glazer R.A, McCarthy K.J (1996) Metamorphic responses to natural substrata in a gastropod larva: decisions related to postlarval growth and habitat preference. Journal of Experimental Marine Biology and Ecology, 205: 229-243

- Strathmann M.F (1987) Reproduction and development of marine invertebrates of the northern pacific coast: Data and methods for the study of eggs, embryos, and larvae. University of Washington Press.

- Strathmann R.R (1971) The feeding behavior of planktotrophic echinoderm larvae: mechanisms, regulation, and rates of suspension feeding. Journal of Experimental Marine Biology and Ecology, 6: $109-160$

- Strathmann R.R (2014) Culturing larvae of marine invertebrates. In: Carroll J.D, Stricker A.S (eds): Developmental Biology of the Sea Urchin and Other Marine Invertebrates: Methods and Protocols,: 1-25. Humana Press, Totowa, N.J.

- Strathmann R.R, Fenaux L., Sewell A.T, Strathmann M.F (1993) Abundance of food affects relative size of larval and postlarval structures of a molluscan veliger. The Biological Bulletin, 185: 232-239

- Strathmann R.R, Fenaux L., Strathmann M.F (1992) Heterochronic developmental plasticity in larval sea urchins and its implications for evolution of non-feeding larvae. Evolution,: 972-986 
- Strathmann R.R, Jahn T.L, James R.C.F (1972) Suspension feeding by marine invertebrate larvae: Clearance of particles by ciliated bands of a rotifer, pluteus, and trochophore. Biological Bulletin, 142: 505-519

- Suer A.L, Phillips D.W (1983) Rapid, gregarious settlement of the larvae of the marine echiuran Urechis caupo Fisher \& MacGinitie 1928. Journal of Experimental Marine Biology and Ecology, 67(3): 243-259

- Switzer-Dunlap M. (1978) Larval biology and metamorphosis of aplysiid gastropods. In: Chia F.S, Rice M.E (eds): Settlement and Metamorphosis of Marine Invertebrate Larvae. Elsevier, New York.

- Switzer-Dunlap M., Hadfield M.G (1977) Observations on development, larval growth and metamorphosis of four species of aplysiidae (Gastropoda: Opisthobranchia) in laboratory culture. Journal of Experimental Marine Biology and Ecology, 29: 245-261

- Thompson P.A, Harrison P.J (1992) Effects of monospecific algal diets of varying biochemical composition on the growth and survival of pacific oyster (Crassostrea gigas) larvae. Marine Biology, 113: 645-654

- Thorson G. (1950) Reproductive and larval ecology of marine bottom invertebrates. Biological Reviews, 25:1-45

- Thorson G. (1961) Length of pelagic larval life in marine bottom invertebrates as related to larval transport by ocean currents. (Oceanography). Amer. Ass. Adv. Sci., 67: 455-474

- Thorson G. (1966) Some factors influencing the recruitment and establishment of marine benthic communities. Netherlands Journal of Sea Research, 3: 267-293

- Toonen R.J, Pawlik J.R (2001) Settlement of the gregarious tube worm Hydroides dianthus (Polychaeta: Serpulidae). II. Testing the desperate larva hypothesis. Marine Ecology Progress Series, 224: 115-131

- Valiela I. (1984) Marine Ecological Processes. Springer-Verlag, Berlin and New York.

- Vance R.R (1973) On reproductive strategies in marine benthic invertebrates. American Naturalist,: 339-352

- Vos J.H, Ooijevaar M.A.G, Postma J.F, Admiraal W. (2000) Interaction between food availability and food quality during growth of early instar chironomid larvae. Journal of the North American Benthological Society, 19: 158-168

- Voss N.A (1959) Studies on the pulmonate gastropod Siphonaria pectinata (Linnaeus) from the southeast coast of Florida. Bulletin of Marine Science, 9: 84-99 
- Wacker A., von Elert E. (2002) Strong influences of larval diet history on subsequent postsettlement growth in the freshwater mollusc Dreissena polymorpha. Proceedings of the Royal Society of London B: Biological Sciences, 269(1505): 2113-2119

- Walne P.R (1956) Experimental rearing of the larvae of Ostrea edulis L. in the laboratory. Fishery Invest., London (Series II) 20: 1-23

- Walne P.R (1963) Observations on the food value of seven species of algae to the larvae of Ostrea edulis. I. Feeding Experiments. Journal of the Marine Biological Association of the United Kingdom, 43: 767-784

- Walters L.J, Wethey D.S (1996) Settlement and early post-settlement survival of sessile marine invertebrates on topographically complex surfaces: the importance of refuge dimensions and adult morphology. Marine Ecology Progress Series, 137:161

- Watanabe J.M (1984) The influence of recruitment, competition, and benthic predation on spatial distributions of three species of kelp forest gastropods (Trochidae: Tegula). Ecology,: 920-936

- Weber J.C, Epifanio C.E (1996) Response of mud crab (Panopeus herbstii) megalopae to cues from adult habitat. Marine Biology, 126: 655-661

- Wehrtmann I.S (1991) How important are starvation periods in early larval development for survival of Crangon septemspinosa larvae? Marine Ecology Progress Series, 73: 183-190

- Werner S., Rothhaupt K-O. (2007) Effects of the invasive bivalve Corbicula fluminea on settling juveniles and other benthic taxa. Journal of the North American Benthological Society, 26: 673680

- West T.L, Costlow J.D (1987) Size regulation in larvae of the crustacean Balanus ebuneus (Cirripedia: Thoracica). Marine Biology, 96: 47-58

- Wethey D.S (1986) Ranking of settlement cues by barnacle larvae: influence of surface contour. Bulletin of Marine Science, 39: 393-400

- Wieczorek S., Todd C. (1997) Inhibition and facilitation of bryozoan and ascidian settlement by natural multi-species biofilms: effects of film age and the roles of active and passive larval attachment. Marine Biology, 128: 463-473

- Wikfors G.H, Twarog J.W, Ukeles R. (1984) Influence of chemical composition of algal food sources on growth of juvenile oysters, Crassostrea virginica. The Biological Bulletin, 167: 251263

- Wilson D.P (1968) The settlement behaviour of the larvae of Sabellaria alveolata (L.). Journal of the Marine Biological Association of the United Kingdom, 48: 387-435 
- Zhao B., Qian P-Y. (2002) Larval settlement and metamorphosis in the slipper limpet Crepidula onyx (Sowerby) in response to conspecific cues and the cues from biofilm. Journal of Experimental Marine Biology and Ecology, 269: 39-51

- Zimmer R.K, Butman C.A (2000) Chemical signaling processes in the marine environment. The Biological Bulletin, 198: 168-187

- Zischke J. (1974) Spawning, development and growth in the pulmonate limpets Siphonaria pectinata Linnaeus, 1758 and Siphonaria alternata Say, 1822. Veliger, 16: 399-404 


\section{APPENDIX. Pilot studies for optimising laboratory culture techniques for Siphonaria australis}

Several preliminary studies were invested into trials to optimise culture methods for $S$. australis. Although time-consuming and labour-intensive, it is clear that I would not have been able to achieve the full culture of this species without the knowledge I received through these preliminary tests. The methods I initially began with were obtained from Strathmann (1987), which reviews ideal culturing methods across a wide range of marine invertebrates, as well as following published methods which have been used by others in my lab group, all of which had been successfully used in many studies of other species (e.g. Phillips, 2002; 2004; Phillips \& Shima, 2006). However, when these methods proved incapable of maintaining larval survival in Siphonaria, I searched for other resources and found a study on the larval culturing of aplysiid gastropods, which described that some techniques used for culturing other larvae were not optimal for gastropod larvae (Switzer-Dunlap \& Hadfield, 1977), so I subsequently applied this information to my culturing method for S. australis.

First Trial Set-Up: Using large volume jars and a mechanised stirring system

Initially, larval cultures were maintained in $2 \mathrm{~L}$, wide-mouthed glass jars, used in conjunction with plastic paddles and a motorised stirring system which continuously, but gently, stirred cultures and kept food and larvae in suspension (see: Strathmann, 1987: pg. 15). To change the water in the cultures I used the reverse-siphoning /sieving method described in Strathmann (1987) where a small tube, with a filter mesh on one end, was immersed in the culture water and the old culture medium was slowly siphoned out to a low level. The mesh retains the larvae in the jar. Clean filtered seawater (FSW) was then poured as gently as possible into the jars back to $2 \mathrm{~L}$.

The main issue with vessels of this size was that it was not possible to observe larvae daily; rather, larvae were being checked only once a week. Unfortunately, using this set up resulted in larval numbers plummeting between water changes, either due to high mortality/damage, or larval loss through transfer. The initial mesh size of the reverse-siphon filter $(75 \mu \mathrm{m})$ may have contributed to the problem, so the mesh size was reduced to $48 \mu \mathrm{m}$. 
Another concern was the frequency of water changes. Initially, water changes were done every third day, causing increased larval losses through transfer, and so water changes were reduced to once a week. However, at this frequency, jars became dirty/contaminated quickly. Alongside this, jars were not able to be fully cleaned/scrubbed out without moving larvae into other temporary containers, risking further larval loss.

It was also suspected that high larval loss/mortality may have partially been due to the motorised paddle stirring system. When larvae were checked for measurements and survival, they were often clumped together by algal particles or by other individuals, potentially impacting swimming and feeding rates. According to Strathmann (1987), a stirred culture develops evenly, has better resistance to fouling, and keeps food suspended and unclumped throughout the vessel, however these were not the conditions I observed in my cultures with this particular stirring mechanism. Switzer-Dunlap \& Hadfield (1977) found that large vessels with a motorised paddle system either provided no advantage or were detrimental to maximal larval survival in aplysiid larvae, so they maintained their cultures, without agitation or stirring, in 1000 and $600 \mathrm{~mL}$ beakers. This supported my choice to reduce vessel sizes and remove the paddle stirring mechanism completely.

Second Trial Set-Up: Using small volume bowls and no stirring

Before deciding the final vessel sizes, I decided to raise and observe the progress of larvae immediately after hatching, to gain a better understanding of what was causing huge larval losses. I raised a small cohort of larvae (50-150 individuals) in glass bowls of 100mL FSW. This proved to be beneficial as I was able to fit the entire bowl beneath a dissecting microscope and observe larvae without disturbing them. Larvae were incredibly fragile and notorious for clumping immediately posthatching, and that "larval stickiness" reduced as larvae aged. Undertaking water changes in these smaller vessels was easier; I could gently pipette individual larvae from one dish to another with very little larval loss, whilst simultaneously counting survivors confidently. In the end, although raising larvae in these small glass bowls had advantages, it limited the number I could culture. I concluded that $500 \mathrm{~mL}$ beakers would be a suitable compromise, as I could increase the larval densities in each vessel, water changes would still be gentle, and it would still be possible to observe larvae beneath the compound microscope. The water changing method was refined to what is written in Chapter 2.

In regards to culture densities, Strathmann (1987) suggests resisting the temptation to keep too many larvae in a vessel, as overcrowding may slow development and produce abnormalities. She suggests that for stirred cultures, densities of $1-3$ larvae/mL per $100 \mathrm{~mL}$ are often reasonable. For my initial 
trials in $2 \mathrm{~L}$ vessels, cultures were at a density of 1 larvae/mL. During my study of observing larvae in glass bowls of $100 \mathrm{~mL}$, I had set up three different larval densities; 0.5 larvae $/ \mathrm{mL}, 1$ larvae per/mL, and 1.5 larvae/mL. I discovered that larvae exhibited greater survival at lower densities and concluded that densities were to be reduced down to 0.5 larvae per $/ \mathrm{mL}$ in the $500 \mathrm{~mL}$ vessels. Similar results have been observed in Capo et al. (2009).

For water changing frequencies, I discovered from raising larvae in small glass dishes, that larval mortalities were higher if water changes occurred in the first week of post-hatching development. Although this risked greater water fouling, it was shown that lower larval densities resulted in less fouling. I concluded that water changes would not occur in the first week of post-hatching development, to allow time for larvae to feed, grow, and increase resilience to external factors.

A final issue was the tendency for larvae to become trapped in the surface tension of the water, especially in still-water cultures. According to Switzer-Dunlap \& Hadfield (1977) and Bonar \& Hadfield (1974), they favoured sprinkling cetyl alcohol sparsely on culture surfaces, a method they obtained from Hurst (1967). This substance was shown to effectively decrease surface tension without causing a toxic effect. When I incorporated cetyl alcohol flakes into the cultures, less larvae became trapped in the surface tension compared to when it was absent. To our current knowledge, there is no method that guarantees total prevention of veliger larvae getting trapped in the surface tension.

\section{Third Trial Set-Up: Bubblers as an alternative stirring system}

I trialled an alternative stirring method to promote food and larval suspension using a gentle bubbling system. Four air pumps, each with two outlets (Model: Hailea ACO-2204; 156 x 95 x 75mm) were connected to either a 2- or 3-way air control valve. Each air control valve was then connected with tubing to an air stone. In order to prevent bubbles from the air stone potentially damaging larvae, the air stones were placed into a plastic tube $(162 \times 27 \mathrm{~mm})$ that was left exposed at one end and covered in $48 \mu \mathrm{m}$ mesh at the other (Fig. A1a). Approximately $50 \mathrm{~mm}$ from the mesh end, four holes were drilled into the pipe into which a $4 \mathrm{~mm}$ black adaptor nozzle was inserted and glued into each one (Fig. A1b) to allow for bubbles to escape and "stir" the water. The pipe needed to be held stable within the beaker, so a $100 \mathrm{~mm} \times 100 \mathrm{~mm}$ perspex square was used, with a hole in the middle suited to fit the pipe (Fig. A1c). The entire apparatus was inserted into a beaker after larvae had been pipetted into them. (Fig. A2). 


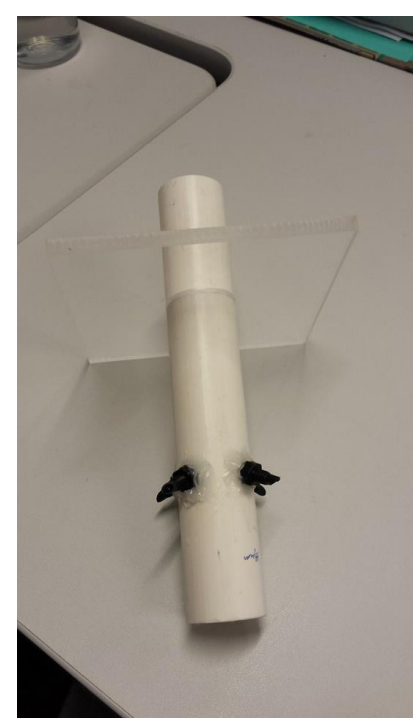

(a)

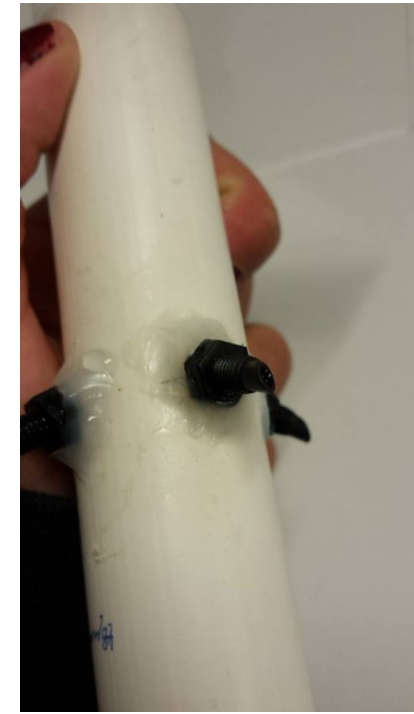

(b)

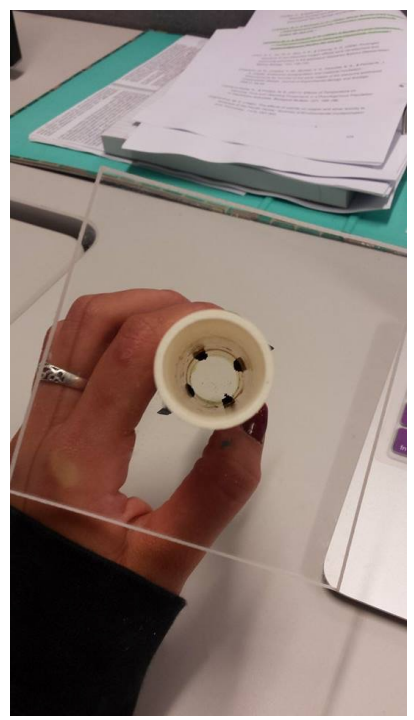

(c)

Figure A1. (a) Overall bubbling apparatus measuring 670 x 27mm; nozzles drilled and glued approx. $50 \mathrm{~mm}$ from meshed end of tube; (b) closer view of the black adaptor nozzles glued onto pipe; (c) bird's eye view of apparatus, showing meshed end and perspex surrounding pipe. Photos taken by: S. Marinus, 2015.

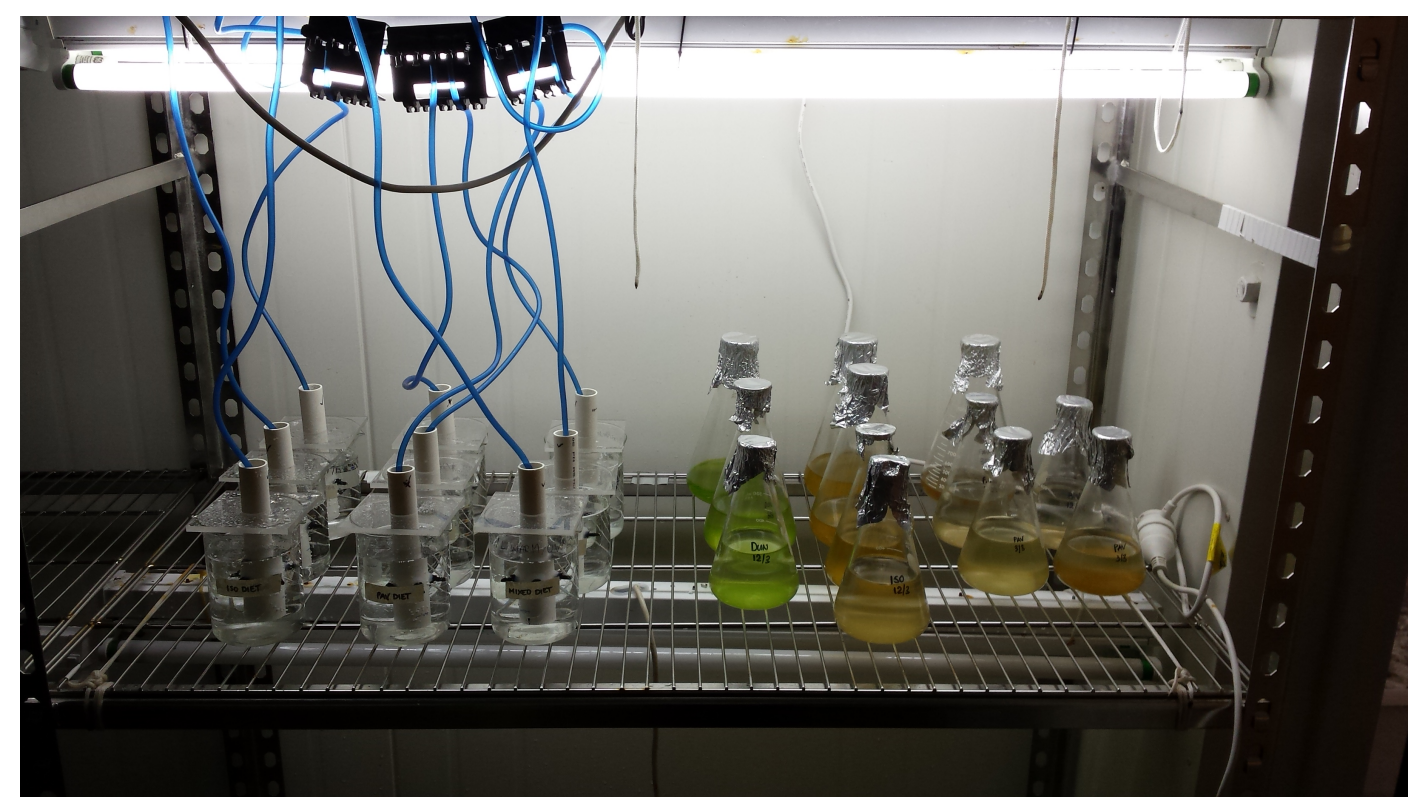

Figure A2. Experimental set up incorporating bubbling mechanism in beakers of culturing larvae. Photo taken by: S. Marinus, 2015. 


\section{Trial Runs}

Two trials had to be repeated due to unforeseen circumstances, which was unfortunate because the duration of every trial is approximately one month (the length $\mathrm{f}$ the larval period), so when a trial had to be repeated it resulted in the loss of a substantial amount of time.

The first trial that required repetition was that of discovering the optimum food concentration defined in Chapter 2. This trial was first conducted in March 2015 and consisted of nine 500mL beakers, with three replicates per treatment. This trial used the bubbling system mentioned above. Only one egg mass was used for this trial, and the culture was maintained in the temperature-controlled room at $15^{\circ} \mathrm{C}$. When the egg mass reached hatching stage, 250 larvae were individually pipetted into each of the nine beakers. During the trial, only five larvae per beaker were measured for growth. There was very high mortality in this run, which compromised the resulted (Fig. A3), and the experiment had to be repeated. One potential cause of high larval mortalities was the bubbling mechanisms, so it was removed in the next trial run. I chose to stir the cultures by hand instead, once to several times a day, as this was the gentlest stirring method possible for ensuring high larval survival. The second, successful attempt is what is written in Chapter 2.

The second trial that had to be repeated was that of discovering the optimum food concentration, which was first conducted in November 2015. The first run consisted of sixteen 500mL beakers, with four replicates per treatment. Larval density was increased from 0.5 larvae $/ \mathrm{mL}$ to 1 larvae/mL, with 500 larvae pipetted into each beaker. Two and a half weeks into the trial an unknown bacterial infection entered the experiment, where a white, gelatinous film formed on the bottom of the beakers and trapped the larvae, causing high mortalities. It remains unknown as to the cause of this infection, or how it got introduced into the cultures. The trial was terminated. I also decided to return larval densities back to 0.5 larvae/mL, to keep conditions consistent with the diet composition trial. The second successful attempt for this trial is written in Chapter 2.

\section{Conclusion}

The larvae of Siphonaria australis are far more delicate that previously thought, particularly in the first week post-hatching. Providing them with an incredibly gentle, clean environment that simultaneously allows observation of the stages of early development has proven to be the best method for the successful larval culture of this species in laboratory conditions. These preliminary 
studies provided crucial information on what is required for the successful culture of this species, in terms of ideal densities, vessel sizes, stirring mechanisms, and water change frequencies.

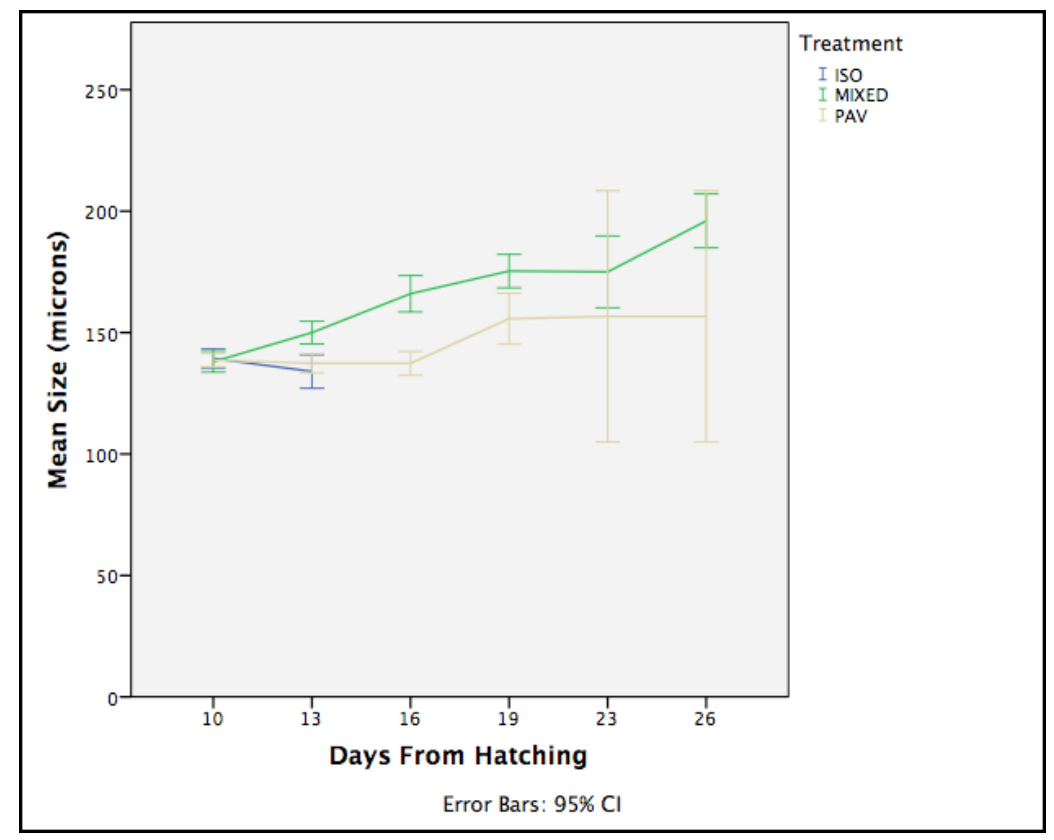

(a)

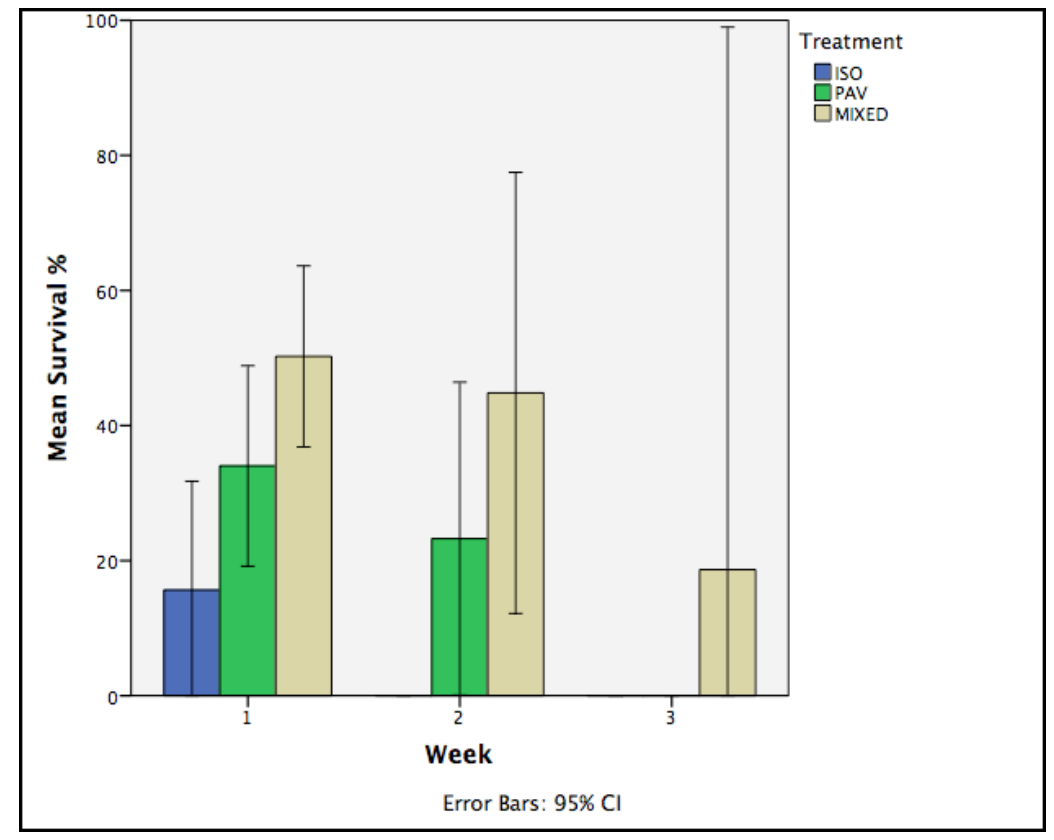

(b)

Figure A3. Statistical analyses of algal diet trial in March 2015: (a) Mean S. australis larval size ( $\mu \mathrm{m})$ when subjected to different algal diets over time $( \pm S E), n=40$ per treatment per days from hatching; (b) non-accumulated survival percentage of $S$. australis over time (grouped into weeks), $\mathrm{n}=3$ per treatment per water change (twice a week). 